Alice Cristina Mondin

Caracterização Toxinológica de Peçonhas do Bagre Marinho Cathorops spixii (Ariidae)

São Paulo

2007 
Alice Cristina Mondin

\section{Caracterização Toxinológica de Peçonhas do Bagre Marinho Cathorops spixii (Ariidae)}

Dissertação apresentada ao Instituto de Biociências da Universidade de São Paulo, para a obtenção de Título de Mestre em Ciências, na Área de Fisiologia Geral.

Orientador(a): Mônica Lopes Ferreira

São Paulo 


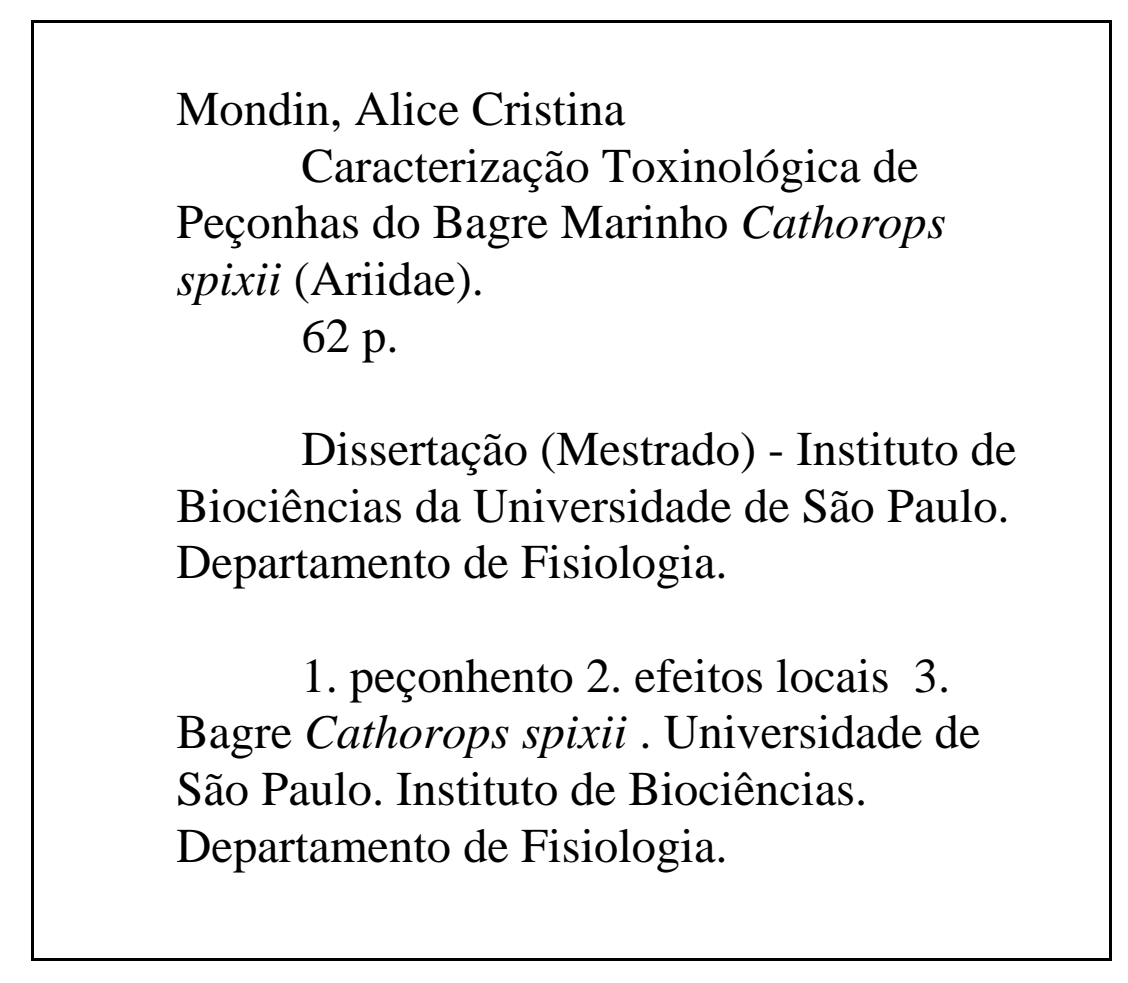

\section{Comissão Julgadora:}




\section{Dedicatória}

Ao mar. Que de tão grandioso, me obrigou a olhar primeiro para suas pequenas, porém não menores, riquezas. 


\section{Epígrafe}

As coisas tangíveis tornam-se

insensíveis à palma da mão.

Mas as coisas findas

Muito mais que lindas,

Essas ficarão.

"Carlos Drummond de Andrade" 


\section{Agradecimentos}

Palavras, jamais expressarão com a intensidade devida a importância das inúmeras pessoas que me acompanharam nestes 3 anos de estrada. Mas, definitivamente é preciso publicar minha gratidão à(os):

- Minha família, especialmente meus pais, meu irmão e meus avós Antonia e Amadeu. Pela criação, apoio, incentivo e, sobretudo, imenso amor;

- Minha orientadora, Mônica, pelo exemplo de pesquisadora, de dedicação, simplicidade e alegria. E especialmente pelos momentos de extrema compreensão (que sempre vieram sem hesitar);

- Dr. José Carlos de Freitas pela “co-orientação” e pelo cavalheirismo de sempre;

- Dr. e amigo Marcos Junqueira, pelo exemplo de vida, pelo imenso carinho, pelas discussões, pelas histórias repetidas, pelos infinitos momentos na sala de experimentos, pela oportunidade de compartilhar minha história com você;

- André Zaharenko, amigo e pesquisador, por ter sido o responsável pela minha entrada no Butantan. Sem você, este trabalho certamente não existiria;

- Colegas e pesquisadores do Laboratório de Imunopatologia do Instituto Butantan, pelos momentos proporcionados, que sem dúvida, resultaram em crescimento profissional e pessoal;

- Dr. Patrick Spencer pelas aventuras no FPLC;

- Dra. Roxane pela acolhida no laboratório, com suas bactérias...;

- Fernandinha Bruni, pela acolhida e apoio imensurável nos trabalhos;

- Dras. Maísa e Isabelle; e Drs. Geraldo e Diego, pelas infinitas discussões científicas. E aos amigos Maísa, Belle, Geralds e Diego, por todas as outras horas, impossíveis de descrever;

- Drs. Renato de Jesus e Samir Rolim, pelo apoio, por acreditarem no meu trabalho e incentivarem meu crescimento;

- Meus amigos do peito, de Botucas e da USP, em especial à Cyn;

- E por último, mas não menos importante, ao meu amor, companheiro de todos os momentos...e à minha segunda maravilhosa família. 


\section{- Índice}

INTRODUÇÃ O............................................................................................8

1.1. ACIDENTES COM PEIXES PEÇONHENTOS ........................................10

1.2. CATHOROPS SPIXII - O BAGRE AMARELO ..................................................12

OBJETIVOS.......................................................................................................................18

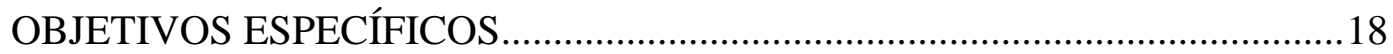

MATERIAIS E MÉTODOS ….........................................................................19

3.1. COLETA DOS PEIXES PARA OBTENÇÃO DAS PEÇONHAS .................19

3.2. DOSAGEM DA CONCENTRAÇÃO PROTÉICA.........................................20

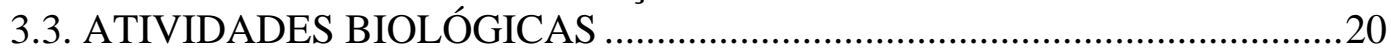

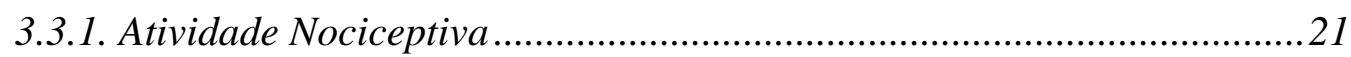

3.3.2. Atividade Edematogênica .....................................................................22

3.3.3. Alteração na Permeabilidade Vascular....................................................22

3.3.4. Alterações na Microcirculação e em Fibras Musculares..........................23

3.3.5. Atividade Proteolítica .......................................................................24

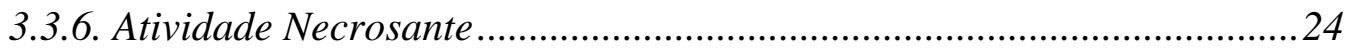

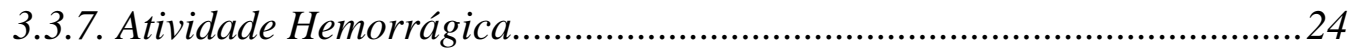

3.4. ELETROFORESE DE PROTEÍNAS (SDS-PAGE) ....................................25

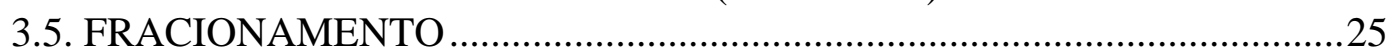

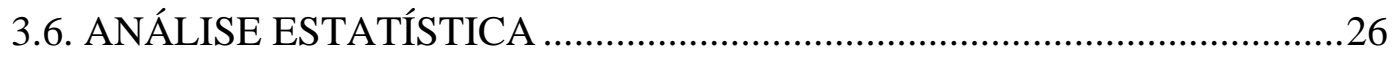

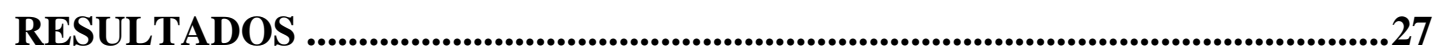

4.1. COLETA DOS PEIXES, OBTENÇÃO E DOSAGEM PROTÉICA DAS

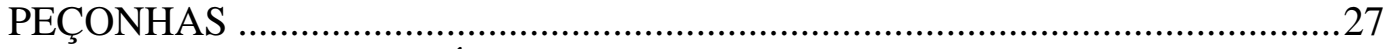

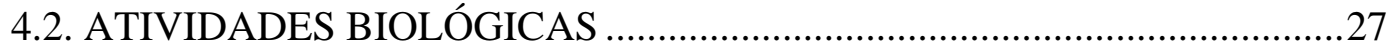

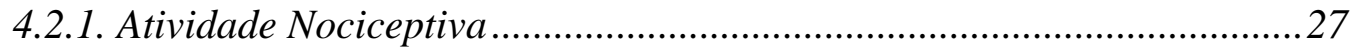

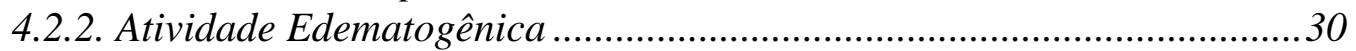

4.2.3. Alteração na Permeabilidade Vascular...................................................32

4.2.4. Alterações na Microcirculação e em Fibras Musculares..........................33

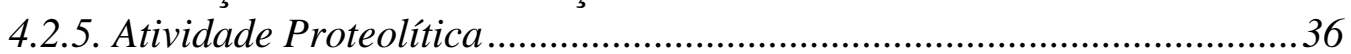

4.2.6. Atividades Necrosante e Hemorrágica ....................................................36

4.3. ELETROFORESE DE PROTEÍNAS (SDS-PAGE) ....................................36

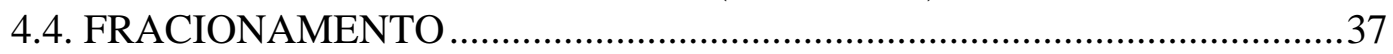

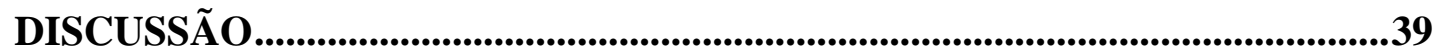

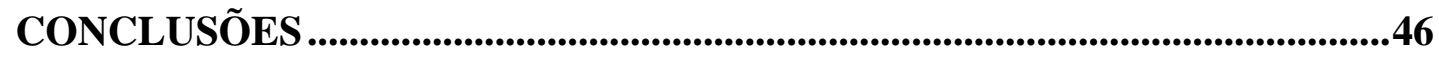

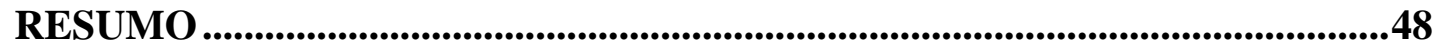

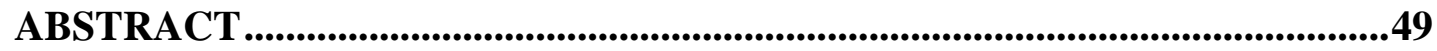

REFERÊNCIAS BIBLIOGRÁFICAS........................................................50

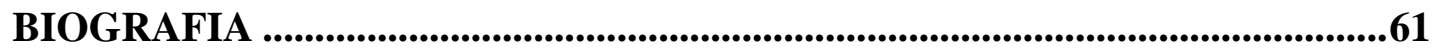




\section{Introdução}

Em todos os níveis da escala filogenética, os seres vivos apresentam comportamentos de ataque e defesa que incluem a produção de substâncias repelentes, paralisantes ou com outras ações biológicas. Estas substâncias na maioria das vezes apresentam uma grande variedade de toxinas que são responsáveis pela sintomatologia observada nos envenenamentos e pelas complexas relações ecológicas existentes entre os organismos.

Os recursos defensivos químicos empregados pelos organismos nessas relações ecológicas geram reações importantes resultando na diversificação dos ecossistemas e na evolução das espécies (Freitas, 1999). A evolução acidental de uma via metabólica resultando, por exemplo, na produção de uma substância nociva para outros membros da comunidade daria uma vantagem seletiva para o clone que adquiriu essa capacidade, e o decréscimo da predação desse organismo induziria um aumento da concentração destes compostos na natureza (Kittredge et al., 1974), assim as toxinas ganharam espaço no processo evolutivo.

Russel (1967, 1971) enfatizou que os animais venenosos ou peçonhentos são encontrados em cada filo. E embora acreditasse que as aves fossem exceção, há relatos de 1800 sobre uma ave peçonhenta (Pitohui dichrous) encontrada em Nova-Guiné.

O estudo de toxinas de animais esteve voltado principalmente para os animais terrestres, como serpentes, aranhas e escorpiões, pela gravidade do acidente que causam e pela proximidade da convivência com o homem. Atualmente, as pesquisas com estes animais terrestres encontram-se bastante desenvolvidas. Muitos dos mecanismos de ação dos envenenamentos já foram descritos, e hoje, busca-se nessas peçonhas 
e venenos, novas substâncias que auxiliem a desvendar os processos fisiológicos associados à sintomatologia clínica dos acidentes; e também novas biomoléculas que possam resultar em novos medicamentos.

Trabalhos realizados com animais marinhos peçonhentos são um pouco mais recentes, mas demonstram que eles representam uma vasta fonte de toxinas e outras substâncias naturais de interesse biomédico, que podem se tornar úteis como ferramentas de pesquisa ou futuros medicamentos. (Olivera et al., 1990; Nuijen et al., 1999; Rinehart, 2000; Cvetkovic, 2002; Scotto, 2002; Van-Kesteren et al., 2002).

Além disso, nos últimos anos, dados epidemiológicos mostram um aumento no número de indivíduos acidentados com animais marinhos peçonhentos, principalmente trabalhadores da área de pesca e banhistas. (Haddad Jr. et al., 2003). As potentes toxinas presentes nesses animais colocam em risco a saúde pública devido aos quadros patológicos que provocam nas situações de envenenamento, dessa maneira, torna-se importante a realização de mais estudos que desvendem os mecanismos de ação dessas peçonhas.

Devido à ampla linha costeira brasileira (aproximadamente $7400 \mathrm{Km}$ ), com grande diversidade de fauna, é natural que muitos animais potencialmente perigosos entrem em contato com seres humanos devido ao grande afluxo de banhistas às praias e ao incremento à pesca comercial e esportiva, além de atividades de lazer, como mergulho autônomo e pesca submarina.

Estes animais aquáticos capazes de provocar acidentes em seres humanos, reunidos em função e gravidade dos acidentes, são poríferos, cnidários, vermes, moluscos, equinodermos, crustáceos, peixes e répteis (Haddad Jr., 2000), podendo-se destacar os peixes. 
Peixes constituem quase metade do número de vertebrados da Terra (Nelson, 1984), sendo aproximadamente 22.000 espécies. Destas, mais de 200 são espécies de peixes marinhos são confirmadas ou supostamente peçonhentas (Russel, 1996). A vasta maioria destes peixes é não migratória, se movimenta pouco e tende a viver em habitat protegido e em águas rasas (Maretic, 1988). Foi sugerido que essa tendência à inatividade está ligada à evolução de um aparato peçonhento (Cameron et al., 1973) apud (Church \& Hodgson, 2002).

Praticamente todas as famílias e gêneros de peixes peçonhentos têm representantes nos mares e rios do Brasil (Haddad Jr., 2002). Possuem importância médica pelos acidentes que provocam em humanos, uma vez que são incapacitantes e mantêm a vítima afastada do trabalho por semanas ou mesmo meses, além de acarretar importantes seqüelas pela ausência de uma terapia cientificamente comprovada. Os peixes peçonhentos que mais causam acidentes no Brasil são arraia (Haddad Jr., 2000), bagre (Haddad Jr., 2000), peixe-escorpião (Figueiredo e Menezes, 1978; 1980; Haddad Jr. \& Pardal, 2003) e niquim (Almeida \& Rocha, 1989; Fonseca \& Lopes-Ferreira, 2000; Auto, 1992; Haddad Jr. \& Pardal, 2003; Monteiro et al., 2003).

\subsection{ACIDENTES COM PEIXES PEÇONHENTOS}

Para o acidente produzido por peixes, dá-se o nome de ictismo, podendo ser tanto por peixes venenosos ou peçonhentos. As características encontradas, aparentemente, entre todos as peçonhas de peixes são a labilidade, e a capacidade de causar dor (Church \& Hodgson, 2002).

Embora apenas algumas espécies de peixes peçonhentos sejam capazes de causar mortalidade no homem, muitas outras podem produzir 
envenenamentos severos, geralmente associados à dor considerável, desproporcional ao tamanho da lesão (Klaassen \& Watkins, 1999; Sutherland et al., 2001; O'Connor et al., 2004) e em alguns casos podem ser observados outros sintomas na vítima de acidente, incluindo manifestações locais de eritema e edema, que em alguns casos acometem todo o membro ferido. Nos casos graves segue-se linfagite, reação ganglionar, abscedação e necrose dos tecidos. O ferimento, muitas vezes demora a cicatrizar, pela ação da peçonha, e/ou agravado por infecção bacteriana secundária. Em casos raros pode haver necessidade de amputações. Manifestações sistêmicas podem ocorrer, como fraqueza, sudorese, náuseas, vômitos, vertigens, hipotensão arterial, choque e até óbito.

Os acidentes, nos peixes considerados peçonhentos, geralmente estão relacionados à espinhos ou ferrões, que segundo (Williamson, 1995) apud (Church \& Hodgson, 2002), nos peixes encontram-se, mais comumente, um ou mais espinhos no dorso, porém estes podem ser encontrados também nas regiões peitoral, opercular, pélvica, anal e caudal, dependendo da espécie. Os espinhos encontram-se associados a glândulas secretoras de veneno e/ou recobertos por uma bainha tegumentar glandular.

Atenção especial também vem sendo dada a secreção mucosa (muco) que recobre a pele dos peixes, já que embora normalmente esteja relacionada às funções de lubrificante na locomoção e no desempenho de importantes papéis na formação de cardumes, reconhecimento de indivíduos e até na migração de determinadas espécies (Hara \& Macdonald, 1976), por outro lado, secreções cutâneas com outras atividades biológicas já são conhecidas para inúmeras famílias de peixes, tais como Ostracidae, Grammistidae, Soleidae e Siluridae, agindo como 
defesa química contra predadores (Boylan \& Scheuer, 1967; Randall et al., 1971; Hashimoto \& Oshima, 1972; Bond, 1979; Clark \& George, 1979; Goldberg et al., 1982; Tachibana, 1984), podendo ser capazes de repelir ou incapacitar outros animais marinhos (Klaassen \& Watkins, 1999), e até possuírem propriedades antibióticas (Church \& Hodgson, 2002) e por isso foram chamadas de (ictiocrinotoxinas).

No que se refere às toxinas protéicas derivadas de peixes peçonhentos marinhos, os trabalhos realizados indicam que podem se tratar de novas famílias de proteínas com mecanismos de ação a serem elucidados. Exemplos importantes são os trabalhos realizados com peçonhas dos peixes da família Scorpaenidae (peixes-pedra ou stonefish) encontrados no Indo-Pacífico; com os gêneros de bagres (catfishes) Arius e Plotosus encontrados no Golfo Arábico; e com a peçonha do peixe brasileiro Thalassophryne nattereri (niquim) encontrado nas regiões Norte e Nordeste do Brasil (Lopes-Ferreira et al., 1998, 2000, 2001, 2002, 2004; Facó et al., 2003; Lima et al., 2003; Magalhães et al., 2005, 2006; Grund et al., 2006; Piran-Soares et al., 2007).

\subsection{Cathorops spixii - O BAGRE AMARELO}

Dos peixes peçonhentos do Brasil, os bagres marinhos (família Ariidae) são os que provocam o maior número de acidentes (Haddad Jr., 2000), podendo ser responsáveis por 90\% dos acidentes com peixes peçonhentos marinhos no Sudeste e Sul do Brasil (Haddad Jr. \& Martins, 2006).

Estão largamente distribuídos ao longo de toda a costa, sendo mais abundantes nas regiões Sudeste e Sul (Reis, 1986). Dentre as espécies de bagres encontradas no Brasil, Cathorops spixii (Scmidt, 2004) é uma das 
mais abundantes do litoral sudeste-sul do Estado de São Paulo, onde causa grande parte dos acidentes. Estes ocorrem principalmente quando pescadores manuseiam redes de pesca e quando banhistas pisam em um exemplar que foi descartado morto na praia. A sintomatologia para as espécies brasileiras é caracterizada por dores extremas e prolongadas, câimbra muscular local, paralisia local, edema, gangrena, sudorese, mal estar, febre, náuseas e vômitos (Haddad Jr., 2000). Embora haja tantos acidentes com esses animais, nada se sabe sobre suas peçonhas no Brasil.

Os bagres (Figura 1) são peixes de pequeno a médio porte, que vivem em grupos de cinco a cem espécimes, em locais rasos e de fundo lodoso. O aparato peçonhento inclui um único ferrão (levemente serrilhado) na porção distal de cada nadadeira peitoral e da dorsal e apresentam três diferentes fontes de substâncias tóxicas (Figura 2). O ferrão, sendo dois peitorais e um dorsal, revestidos por um epitélio glandular que produz toxinas; as glândulas axilares, encontradas próximas à base dos espinhos laterais, onde seus produtos são “despejados” através de um poro axilar visível; e o muco (ictiocrinotoxina), que consiste em um material protéico e gelatinoso produzido por células elaboradoras de proteínas denominadas “célulasclub” (Thulesius et al., 1983).

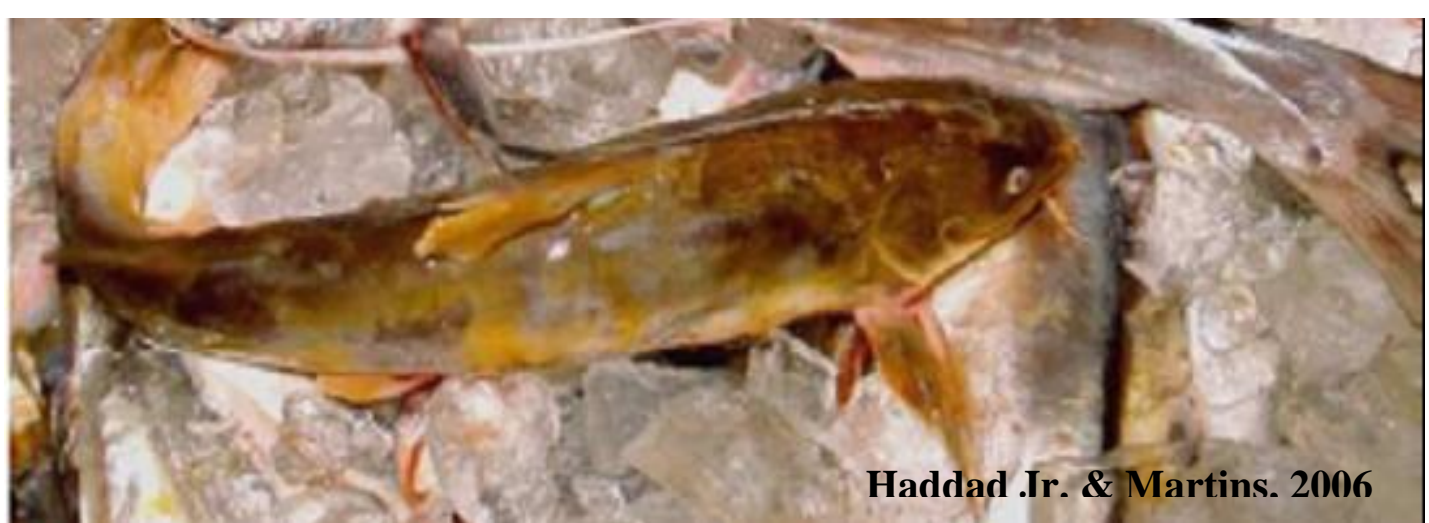

Figura 1. Exemplares de bagre-amarelo (Cathorops spixii) 


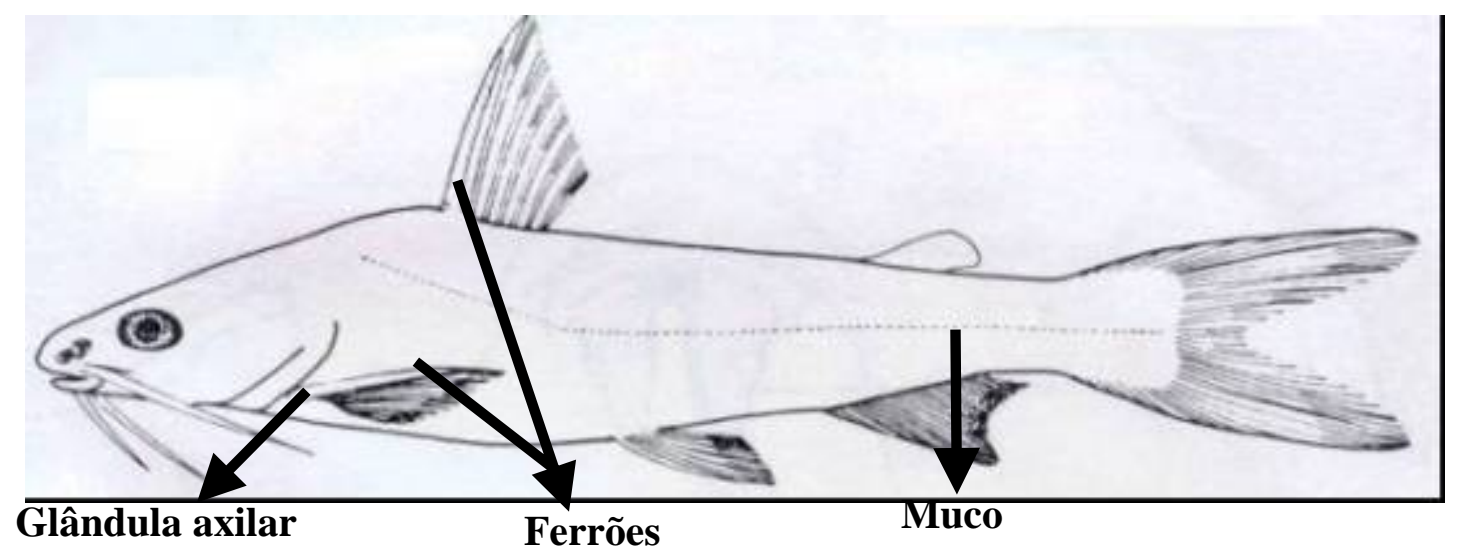

Figura 2. Esquema dos 3 tipos de fontes de substâncias tóxicas encontradas nos bagres marinhos.

As "células-club" estão presentes em abundância nos bagres e produzem toxinas que são liberadas posteriormente para a superfície da pele (Al-Hassan et al., 1985a). A importância do seu conteúdo citoplasmático não está bem definida, embora algumas funções de proteção para o peixe tenham sido sugeridas, como a existência de feromônios específicos que atuam como substâncias de alarme. A avaliação do conteúdo das “células-club” em bagres demonstrou que estas diferem do conteúdo bem como em suas propriedades físicoquímicas, das células produtoras de muco. Também são relatadas ações biológicas e/ou tóxicas em animais experimentais e em células, principalmente as sanguíneas.

Acredita-se que no momento do acidente com bagres, a laceração provocada pela penetração do ferrão, facilite a introdução e absorção das substâncias tóxicas das três possíveis fontes (Pardal, 1999).

Embora a casuística de acidentes com bagres no Brasil seja bastante significativa (Haddad Jr. \& Martins, 2006), apenas recentemente (ver Junqueira et al., 2007) foram publicados estudos sobre as possíveis ações das peçonhas de bagres brasileiros, especialmente do bagre amarelo Cathorops spixii. 
Um dos estudos mais completos para bagres foi realizado com o muco dos gêneros Arius e Plotosus encontrados no Golfo Arábico. Segundo Al-Hassan et al. (1982, 1985a), estes bagres produzem uma secreção protéica através das “células-club” da epiderme quando ameaçado ou injuriado. Como esta secreção é composta principalmente de glicoproteínas, acredita-se que seja elaborada para defesa, não contra predadores, mas contra lesões.

Quando frações solúveis desta peçonha foram injetadas intravenosamente em coelhos, observou-se morte dos animais, além de agregação de plaquetas e síntese de prostanóides (Al-Hassan et al., 1985b, 1987). Também foi comprovado que é composta por fatores vasoativadores (Thulesius et al., 1983; Al-Hassan et al., 1986a), fator aglutinante do plasma (Summers et al., 1985), fator hemolítico (AlLahham et al., 1987), fator hemaglutinante (Al-Hassan et al., 1986b), uma esterase tirosino-específica (Thomson et al., 1989) uma fosforilase (Criddle et al., 1988), uma fosfatase ácida (Thomson et al., 1990), esterases (Thomson et al., 1984), e um ativador de fosfolipase A (AlHassan et al., 1987a).

Preparações com a peçonha do muco causaram fechamento e aceleração na cura de feridas em humanos e animais de laboratório (AlHassan et al., 1991) e de úlceras diabéticas (Al-Hassan, 1990; Al-Bow et al., 1997). Segundo Kizer (1984), esta peçonha dos bagres contém fatores vasoconstritores e necrosantes. O estudo mais recente (Fahim et al., 2002) demonstra atividade antitumoral. Estudos sobre a do ferrão demonstram a existência de uma toxina protéica letal, apresentando atividades cardiotóxicas e de bloqueio neuromuscular (Auddy et al., 1976). A peçonha glandular apresenta enzimas líticas e diversos fatores com ação sobre o sangue, que assim como a do muco, possui atividades 
bioquímicas e farmacológicas que podem ser facilmente relacionadas com os efeitos fisiológicos observados no acidente. Essas enzimas incluem esterases, fosfatases, fatores hemolíticos que causam contração de músculo liso em artéria umbilicais humanas e induzem resposta depressora in vivo e fatores vasoconstritores. Ao contrário das outras duas, a peçonha da glândula parece ser termoestável (Thulesius et al., 1983).

Todos estes trabalhos demonstram a importância, não só do estudo com as peçonhas de bagre, mas a grande diversidade de ações que estes podem ter e que podem estar direta ou indiretamente relacionadas às conseqüências do envenenamento; bem como ser fonte de inúmeras novas moléculas de interesse para o homem.

Segundo Freitas (1991), o termo peçonha ("venom”, em inglês e “venin” em francês) designa a secreção proveniente de glândula especializada associada ou não a uma estrutura inoculadora. Geralmente são peptídeos e proteínas que atuam por via parenteral e podem ser destruídas quando ingeridas (Freyvogel \& Perret, 1973). Por outro lado, define-se como veneno, toxinas que são acumuladas do alimento, ou são resultado de ação bacteriana, são produtos metabólicos produzidos (por ação bacteriana) ou estocados em órgãos que, em condições naturais, afetam o organismo quando ingeridos e podem também atuar, de modo artificial, por via parenteral.

Assim, partindo da nomenclatura adotada, os bagres possuem 3 fontes de substâncias peçonhentas: o muco, através das células-club; o ferrão, através das células produtoras de peçonha presentes no epitélio glandular que recobre os ferrões; e a glândula axilar.

A fim de padronizar a forma de escrita e aproximar-se às citações internacionais para os bagres, neste trabalho citaremos as substâncias 
peçonhentas produzidas conforme descrito acima, como "peçonha do muco", "peçonha do ferrão" e peçonha da glândula axilar”. Porém ressalta-se que as substâncias peçonhentas são produzidas por glândulas em todos os casos. 


\section{Objetivos}

Dada a importância do estudo das toxinas de animais marinhos, em particular dos peixes e no caso do Brasil, dos bagres marinhos, na compreensão dos acidentes, na possibilidade de melhoria no tratamento, na elucidação de novas substâncias com potencial terapêutico (farmacologia, medicina), na compreensão da biologia e das complexas relações ecológicas, este trabalho objetiva a caracterização de diversas atividades tóxicas das peçonhas do muco e do ferrão do bagre marinho Cathorops spixii.

\section{OBJETIVOS ESPECÍFICOS}

1) Avaliar em modelo murino a indução de:

- Nocicepção;

- Edema;

- Alteração na permeabilidade vascular;

- Hemorragia;

- Necrose;

- Alterações na Microcirculação e em Fibras Musculares;

- Proteólise.

2) Elucidar perfil eletroforético e cromatográfico das peçonhas 


\section{Materiais e Métodos}

\subsection{COLETA DOS PEIXES PARA OBTENÇÃO DAS PEÇONHAS}

Para a coleta dos peixes, das peçonhas e o processamento destes utilizou-se dos procedimentos padronizados por Junqueira \& Mondin (ver Junqueira et al. 2006, 2007).

A coleta dos espécimes de Cathorops spixii foi realizada no complexo Baía-Estuário de Santos e São Vicente, localizado no litoral sul do Estado de São Paulo, onde $C$ spixii é uma das espécies de peixes marinhos mais abundantes. Foram realizadas saídas de barco com pescadores da região e utilizados linha e anzol para a coleta individual. A identificação das espécies foi realizada empregando-se chave de identificação publicada por Figueiredo \& Menezes (1978).

O método de coleta individual foi adotado, já que esta metodologia impede que o peixe se debata demais e perca um pouco do muco, além disso, evita o contato com outras espécies de peixes, o que poderia ocasionar contaminação, como aconteceria num arrasto ou pesca com rede, por exemplo.

Imediatamente após a coleta, cada bagre teve o muco e os ferrões retirados Para a coleta do muco, a pele do bagre foi raspada delicadamente com lâmina histológica. Lembrando que este peixe não apresenta escamas, então esta raspagem delicada permite a coleta apenas de muco, sem causar danos a pele do animal e contaminar a amostra. Para a remoção dos ferrões utilizamos um alicate e os armazenamos em tubos Falcon. 
$\mathrm{O}$ material coletado foi submetido à refrigeração imediata $\left(0^{\circ} \mathrm{C}\right)$ em caixas térmicas com gelo, para o transporte até o Laboratório de Imunopatologia do Instituto Butantan - SP, onde foi processado.

A partir de modificações de Al-Hassan et al. (1985), o processamento dos ferrões também foi padronizado. Estes ferrões foram macerados em PBS estéril (aproximadamente $300 \mu \mathrm{L}$ por ferrão) resultando em um líquido escuro, marrom ou acinzentado. A seguir, foi feita homogeneização, para garantir que todo a peçonha do ferrão se desprenda deste e em seguida a parte óssea é descartada. A seguir, as amostras extraídas são misturadas e homogeneizadas. Subseqüentemente, procedeu-se a centrifugação (13000rpm $/ 0^{\circ} \mathrm{C} / 10 \mathrm{~min}$ ), e o sobrenadante foi coletado e reservado para os experimentos.

O muco raspado da lâmina foi diluído em igual volume de PBS estéril e homogeneizado. Também é feito um pool e a seguir essa mistura é centrifugada nos padrões já descritos e o sobrenadante é coletado.

\subsection{DOSAGEM DA CONCENTRAÇÃO PROTÉICA}

Após processamento das peçonhas aferimos a concentração protéica através de método colorimétrico (Bradford, 1976) usando como padrão soro albumina bovina (Sigma, Chemical Company; ST. Louis, MO, USA).

\subsection{ATIVIDADES BIOLÓGICAS}

Para os ensaios biológicos foram utilizados camundongos da linhagem Swiss, machos, pesando entre 20 e 22 g, cedidos pelo Biotério 
Geral do Instituto Butantan e mantidos no biotério do Laboratório de Imunopatologia com água e ração ad libtum em ciclo claro / escuro de 12h. Os animais foram mantidos em gaiolas com isolador nas condições de umidade, luminosidade e temperatura ideais. Todos os experimentos seguiram as normas aprovadas pela Comissão de Ética em Experimentação Animal.

Para os ensaios, utilizou-se peçonha do muco, ou peçonha do ferrão, ou ainda a mistura de peçonhas (muco mais ferrão) em igual concentração $(\mu \mathrm{g} / \mathrm{mL})$.

\subsubsection{Atividade Nociceptiva}

A atividade nociceptiva foi avaliada segundo o descrito por Hunskaar \& Hole (1987). Camundongos $(n=6)$ foram colocados individualmente sob funis de vidro invertidos localizados sobre uma superfície refletora para facilitar a observação. Após um período de adaptação de pelo menos 10min, os animais receberam injeção intraplantar, em uma das patas posteriores, de diferentes doses das peçonhas (3, 10, 30 ou $60 \mu$ g de proteína em $30 \mu \mathrm{L}$ de PBS estéril). Como controle, grupos foram injetados com $30 \mu \mathrm{L}$ de PBS estéril ou $60 \mu \mathrm{g}$ Albumina/ 30 $\mu \mathrm{L}$ de PBS estéril.

Após a injeção das diferentes doses, foi medida a reatividade, considerada como o tempo gasto, em segundos, em que os animais lambem ou mordem a pata injetada, durante 30min de avaliação experimental. A fim de avaliar as diferentes respostas relacionadas a indução de dor neurogênica (expressa de 0-5min após a injeção) e a dor inflamatória (expressa de 15-30min após a injeção). São apresentados resultados da média, adicionada do desvio padrão, dos tempos de 
reatividade dos animais nos períodos de 0 a 5 min e 15 a $30 \mathrm{~min}$, de três experimentos independentes.

\subsubsection{Atividade Edematogênica}

Para avaliação da atividade edematogênica grupos de camundongos $(n=08)$ receberam injeção intradérmica no coxim plantar de uma das patas traseiras com diferentes doses das peçonhas $(3,10,30$ ou $60 \mu$ g de proteína em $30 \mu \mathrm{L}$ de PBS estéril) e na pata oposta receberam

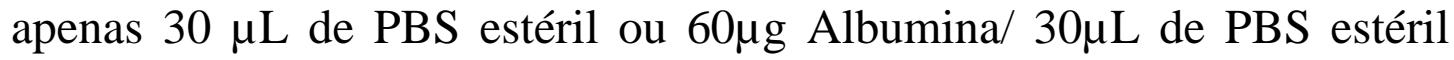
(“controle”). O edema foi avaliado como a diferença de espessura, em milímetros, entre a pata experimental e a pata controle, após 0,$25 ; 0,5 ; 2$, 4 e 6h da injeção (Lima et al., 2003). A espessura da pata foi medida com auxílio de um paquímetro (Mytutoyo). Resultados são expressos como a média da porcentagem de espessura em relação ao grupo controle, adicionada do desvio-padrão.

\subsubsection{Alteração na Permeabilidade Vascular}

As alterações da permeabilidade vascular foram avaliadas através do extravasamento do corante azul de Evans (AE), na cavidade peritoneal dos camundongos ( $n=4), 2$ horas após a injeção intraperitoneal (i.p.) de 10, 30 ou $60 \mu$ g das peçonhas (de muco ou de ferrão) ou solução fisiológica apirogênica. Os animais receberam injeção intravenosa (i.v.), no plexo oftálmico, do corante azul de Evans (20mg/Kg) 20min antes do tempo de avaliação da permeabilidade vascular. Após 2h, os animais foram sacrificados e exsanguinados, a cavidade peritoneal foi lavada com tampão fosfato salina (Phosfate Buffer Saline - PBS) pH 7,2 e o líquido 
de lavagem foi centrifugado a 1200rpm por 5min. A concentração de azul de Evans no sobrenadante foi determinada por espectrofotometria a 620nm (Sirois et al., 1988). Os resultados foram expressos em $\mathrm{mg}$ $\mathrm{AE} / \mathrm{mL}$ e a concentração de $\mathrm{AE}$ foi estimada a partir de uma curva padrão de BSA, de concentração conhecida. Os resultados foram expressos como a média de dois diferentes experimentos adicionada do desvio padrão.

\subsubsection{Alterações na Microcirculação e em Fibras Musculares}

A dinâmica da alteração no sistema microcirculatório e em fibras musculares foi determinada utilizando-se microscopia intravital, por transiluminação do músculo cremaster após a aplicação tópica da

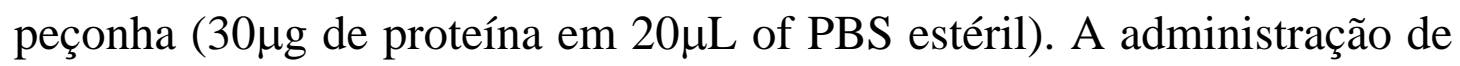
$20 \mu \mathrm{L}$ de PBS estéril foi utilizada como controle. Em três experimentos independentes, camundongos $(n=3)$ foram previamente anestesiados com

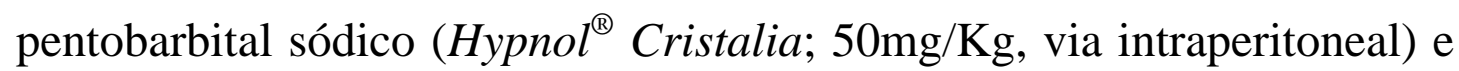
então, o músculo cremaster foi exposto para análise microscópica in situ como descrito por Baez (1973) e Lomonte et al. (1994). Os animais foram mantidos em uma placa termostaticamente regulada para a temperatura de $37^{\circ} \mathrm{C}$, que inclui uma plataforma transparente, na qual o tecido a ser transiluminado, neste caso o cremaster, é colocado. Após a estabilização da microcirculação, o número de células em rolling e os leucócitos que aderem às vênulas pós-capilares são contados após a aplicação tópica da peçonha, até $40 \mathrm{~min}$. As contagens e alterações morfo-fisiológicas no cremaster e no sistema microvascular, são acompanhados em um microscópio óptico (Axiolab, Carl-Zeiss) acoplado a uma câmera fotográfica (Coolpix 990-Nikon) equipada de com objetiva de x10/025 e 1.6 optovar. 


\subsubsection{Atividade Proteolítica}

A atividade proteolítica foi estimada utilizando-se como substrato a caseína, conforme descrito por Mandelbaum et al. (1982). 1mL de caseína (1\%) foram incubados por $2 \mathrm{~h}$ a $37^{\circ} \mathrm{C}$ com $400 \mu \mathrm{L}$ da solução teste, contendo diferentes doses de peçonha (3, 10, 30 ou $60 \mu$ g de proteína) na presença de $0,008 \mathrm{M} \mathrm{CaCl} 2$ (pH 8,8). A reação foi paralisada com ácido tricloroacético 5\% e os peptídeos hidrolisados contidos no sobrenadante, quantificados através do método de Lowry et al. (1951). Uma unidade é definida como a quantidade de enzimas que causa um acréscimo na densidade óptica de 1,0 por minuto a 750nm. Resultados são expressos em U/mg de peçonha de três experimentos independentes.

\subsubsection{Atividade Necrosante}

Avaliada segundo adaptações do protocolo descrito por Ferreira et al. (1992). Grupos de camundongos $(\mathrm{n}=5)$, foram injetados por via

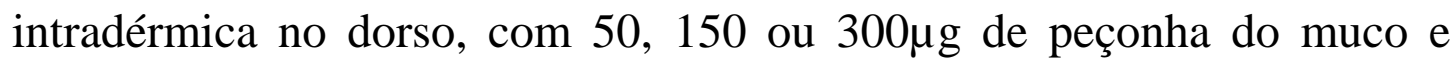
ferrão, diluídos em PBS estéril ao volume final de $50 \mu \mathrm{L}$ e após $72 \mathrm{~h}$ foram sacrificados. O grupo controle foi injetado apenas com PBS estéril.

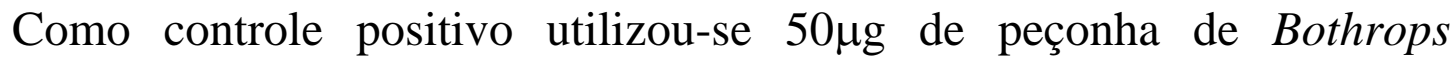
jararaca. A pele do dorso foi removida e transferida para um suporte para medida do diâmetro da lesão. Os resultados são expressos como o produto dos diâmetros \pm o desvio padrão, de três experimentos independentes.

\subsubsection{Atividade Hemorrágica}


Camundongos $(n=5)$, foram injetados por via intradérmica no

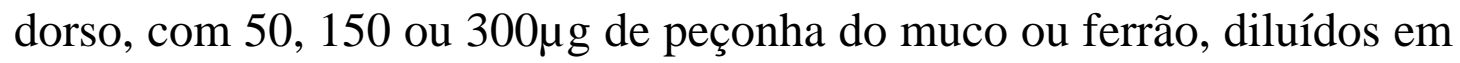
PBS estéril ao volume final de $50 \mu \mathrm{L}$ e após $2 \mathrm{~h}$ foram sacrificados. Como controle dois grupos foram utilizados: um injetado apenas com PBS estéril e o outro com 10 $\mu$ g de peçonha de Bothrops jararaca.

Após o sacrifício, a pele do dorso foi removida e transferida para um suporte para medida do diâmetro da lesão, que foi determinado medindo-se o maior e o menor diâmetros com auxílio de um paquímetro. Rucavado et al., 2000). Os resultados são expressos como o produto dos diâmetros \pm o desvio padrão, de três experimentos independentes.

\subsection{ELETROFORESE DE PROTEÍNAS (SDS-PAGE)}

Após a dosagem de proteínas, as proteínas presentes nas peçonhas de C. spixii foram separadas por eletroforese em gel de poliacrilamida com adição de SDS (SDS-PAGE), conforme Laemmli (1970), em condições redutoras (com adição de 2-mercaptoetanol) e não redutoras. Alíquotas (10 $\mu$ g de proteína) foram diluídas em $20 \mu \mathrm{L}$ de Tampão de Amostra (Tris-HCL pH 6,8, SDS 10\%, glicerol, EDTA e azul de bromofenol), aquecidos a $100^{\circ} \mathrm{C}$ por $5 \mathrm{~min}$ e posteriormente, $15 \mu \mathrm{L}$ da solução foram aplicados em gel de poliacrilamida (12\%). Foi aplicada a voltagem de $180 \mathrm{~V}$, corrente de $20 \mathrm{~mA}$ por $1 \mathrm{~h} 30 \mathrm{~min}$ para a separação das proteínas. A coloração foi feita com Comassie Blue. Como padrão de massa molecular foram utilizados Fosforilase B (97 kDa), Albumina (66 kDa), Ovalbumina (45 kDa), Anidrase carbônica (30 kDa), Inibidor de tripsina (20,1 kDa) e $\alpha$-Lactalbumina (14,4 kDa).

\subsection{FRACIONAMENTO}


Para este ensaio foi utilizado um pool de peçonha. Este foi fracionado por cromatografia de filtração em gel utilizando-se o sistema rápido de cromatografia líquida de proteína (FPLC). Imediatamente antes da cromatografia, $10 \mathrm{mg}$ de peçonha foram diluídos em $500 \mu \mathrm{L}$ de água Milli-Q e a solução centrifugada a 14.000 g por 5 minutos imediatamente antes ao fracionamento. As amostras foram aplicadas em coluna de Gelfiltração (Superdex G-75 - Pharmacia) equilibrada com tampão Tris $\mathrm{NaCl}$ pH 7,5. A eluição das proteínas foi realizada com tampão Tris $\mathrm{NaCl}$ $\mathrm{pH}$ 7,5 durante 45 minutos sob fluxo constante de $1 \mathrm{~mL} / \mathrm{min}$. Os perfis das eluições foram determinados pela medida de absorbância a $280 \mathrm{~nm}$ para cada tubo coletado. As frações contendo as proteínas foram reunidas e dializadas com Tampão Tris $50 \mathrm{mM}$ durante 24 horas a $4^{\circ} \mathrm{C}$ para a retirada do sal e mantidas a $-20^{\circ} \mathrm{C}$ para os experimentos futuros.

\subsection{ANÁLISE ESTATÍSTICA}

Os resultados foram expressos como a média adicionada do desvio padrão. As diferenças estatísticas entre os grupos experimentais e o grupo-controle foram detectadas com o teste-t (não paramétrico). São considerados como significativos os valores de $\mathrm{p}<0,05$. 


\section{Resultados}

\subsection{COLETA DOS PEIXES, OBTENÇÃO E DOSAGEM PROTÉICA DAS PEÇONHAS}

Nossas coletas resultaram em aproximadamente 15 peixes por coleta, rendendo $6 \mathrm{~mL}$ de peçonha do muco e $3 \mathrm{~mL}$ de peçonha do ferrão. A partir do método colorimétrico descrito, obtivemos a concentração protéica das peçonhas, que variou entre as coletas, desde $2 \mathrm{mg} / \mathrm{mL}$ a 36 $\mathrm{mg} / \mathrm{mL}$ de peçonha. Em média a peçonha do muco apresentou-se a 7,8 $\mathrm{mg} / \mathrm{mL}$, enquanto que a peçonha do ferrão, a $8,7 \mathrm{mg} / \mathrm{mL}$. Essas diferenças podem ter sido ocasionadas por variações sazonais e espaciais na captura dos animais.

\subsection{ATIVIDADES BIOLÓGICAS}

\subsubsection{Atividade Nociceptiva}

As peçonhas do muco e do ferrão do bagre C. spixii induziram nocicepção (Figura 3), quando injetados individualmente ou juntos, a partir da concentração de $3 \mu$ g de proteína $/ 30 \mu \mathrm{L}$, alcançando o máximo com a dose de $60 \mu$ g, para a peçonha do muco, do ferrão e para a mistura. A peçonha do muco mostrou ser mais potente que o do ferrão. A mistura resultou em nocicepção em valores muito próximos aos da peçonha do muco. Entretanto a relação de dose dependência foi observada apenas na injeção da mistura das peçonhas.

Com relação às fases neurogênica e inflamatória, o teste da formalina realizado com $30 \mu \mathrm{g}$ das peçonhas revelou que ambos induzem dor neurogênica significativamente superior ao controle e em potências 
semelhantes, porém, quanto à dor inflamatórias, a peçonha do muco mostrou-se muito mais potente que o do ferrão. 


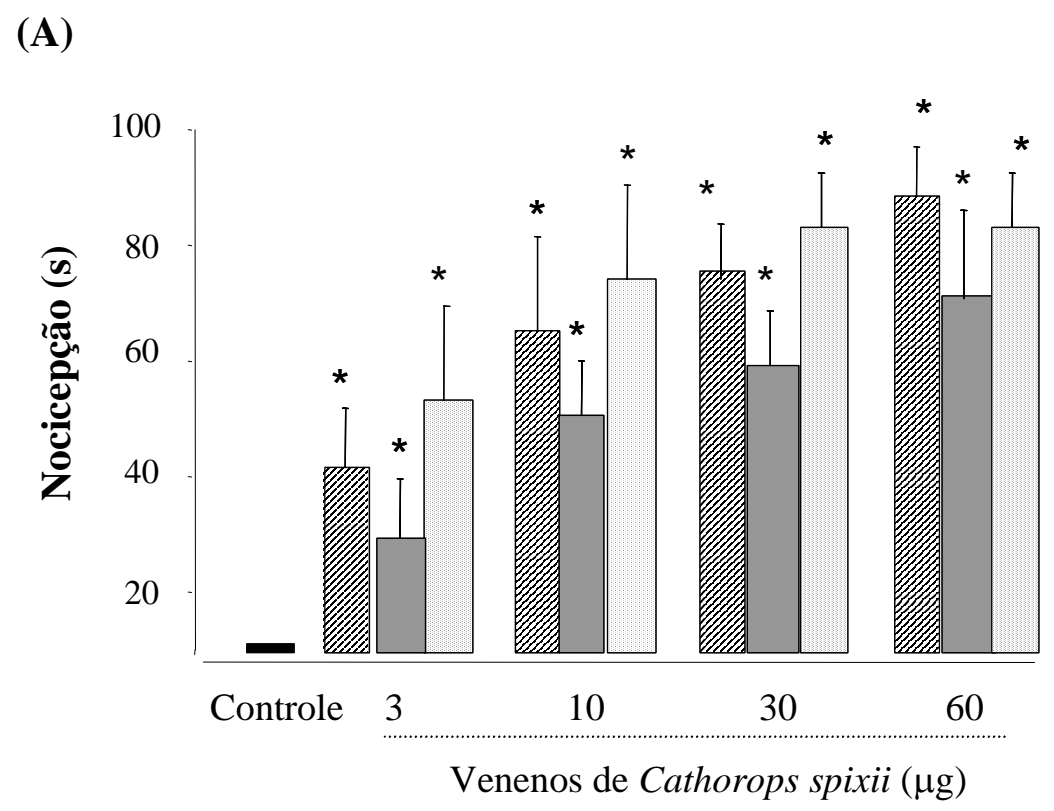

Salina $\square$ Veneno do Muco $\square$ Veneno do Ferrão $\square$ Veneno do Muco + Ferrão

(B)

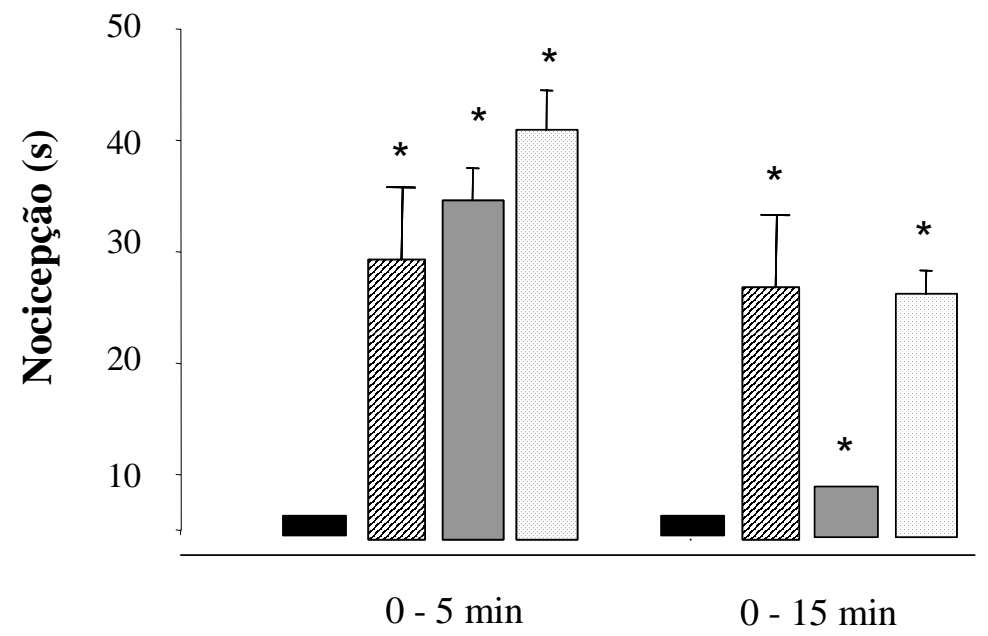

Figura 3. Curva dose-resposta (A) e tempo-resposta (B) da nocicepção induzida

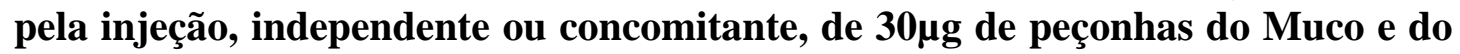

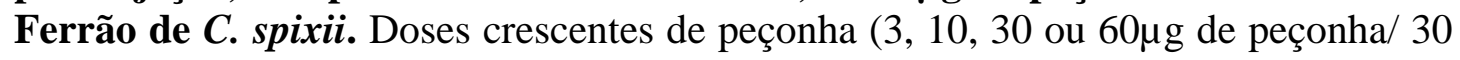
$\mu \mathrm{L}$ de PBS estéril) foram injetadas no coxim plantar de camundongos Swiss machos $(n=5)$. A nocicepção foi determinada durante $30 \mathrm{~min}$, como o tempo em segundos durante o qual os animais lambem ou mordem a pata. Animais injetados somente com PBS estéril foram considerados grupo-controle.

${ }^{*} \mathrm{p}<0,05$ em relação ao grupo-controle. 


\subsubsection{Atividade Edematogênica}

Tanto a peçonha do muco, quanto o do ferrão e a mistura dos dois, foram capazes de induzir edema mais de 30\% maior do que o controle (PBS) mesmo em baixas concentrações (Figura 4). Observou-se dosedependência para a peçonha do muco, do ferrão e da mistura. O pico de edema foi observado em $2 \mathrm{~h}$ tanto para a peçonha do muco quanto do ferrão; também para ambos e em todas as doses testadas. 
(A)

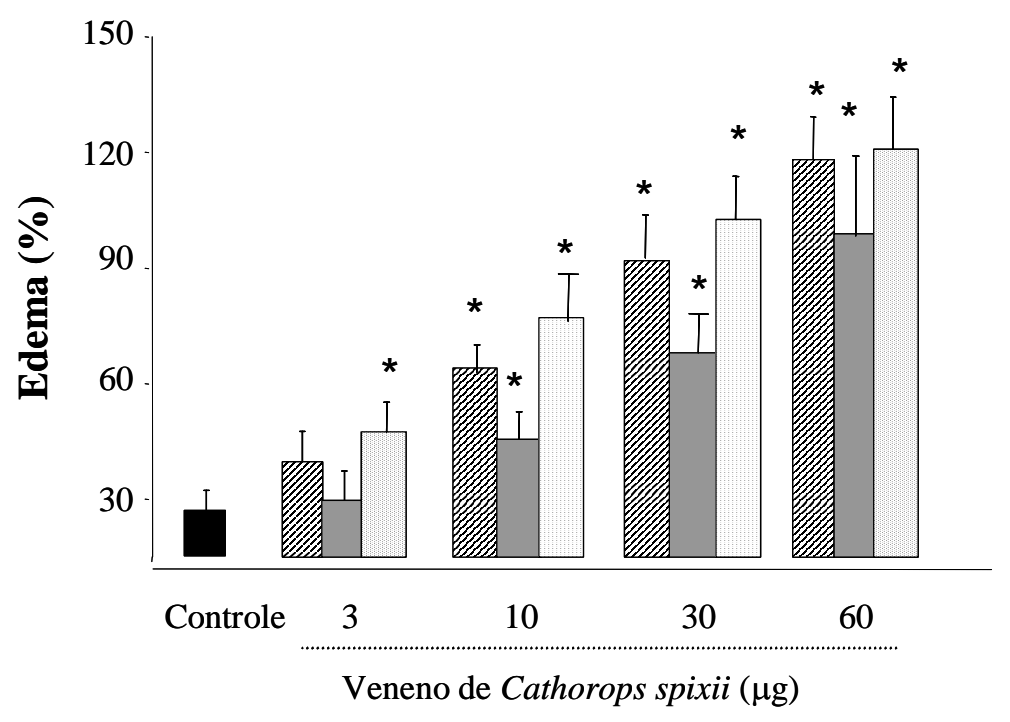

Salina

(B)

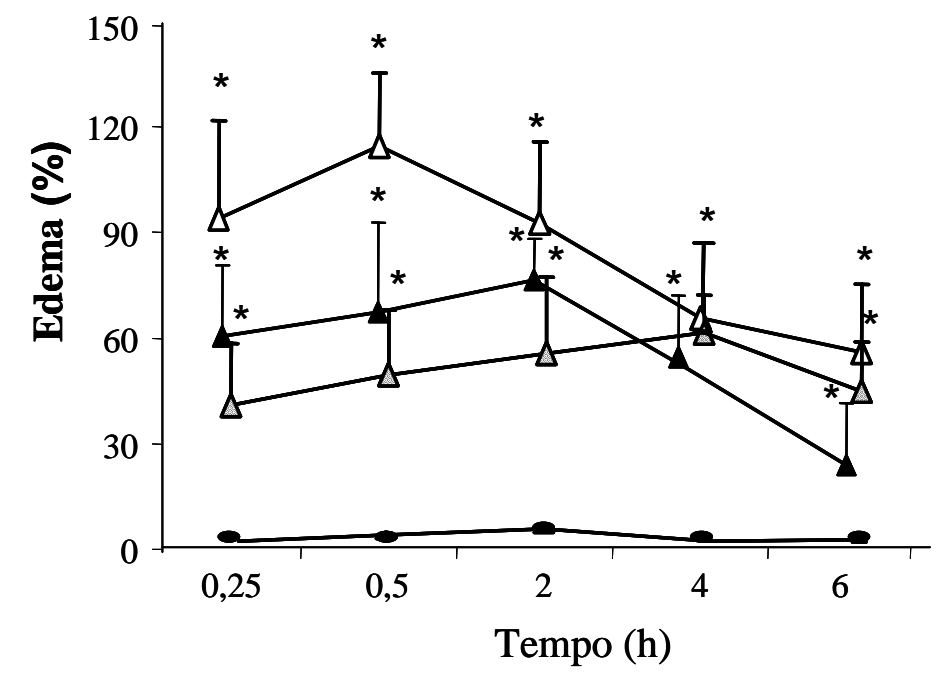

Salina $\boldsymbol{\Delta}$ Veneno do Muco $\Delta$ Veneno do ferrão $\Delta$ Veneno Muco + Ferrão

Figura 4. Edema induzido pelas peçonhas do Muco, Ferrão e Muco + Ferrão de C. spixii. Camundongos Swiss foram injetados no coxim plantar com 3, 10, 30 ou $60 \mu \mathrm{g}$ de proteína/ $30 \mu \mathrm{l}$ de PBS estéril e o edema foi avaliado após 0,25; 0,5; 2; 4 e 6h após a injeção, medindo-se a espessura da pata com paquímetro (Mytutoyo). Animais injetados somente com PBS estéril foram considerados grupo-controle. Em (A) é apresentada a porcentagem de aumento do edema em relação ao controle, provocado pela injeção das diferentes doses após $2 \mathrm{~h}$. Em (B) é apresentada a cinética

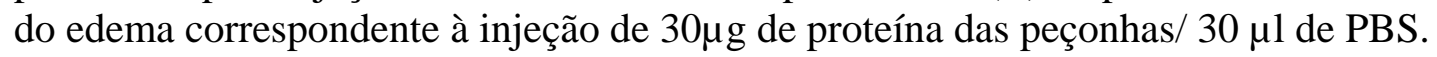
${ }^{*} \mathrm{p}<0,05$ em relação ao grupo-controle. 


\subsubsection{Alteração na Permeabilidade Vascular}

Os resultados mostram (Figura 5) que ambas as peçonhas, em todas as doses testadas, causam aumento da permeabilidade vascular após 2h da injeção na cavidade peritoneal, caracterizado, neste modelo experimental, pelo extravasamento do corante azul de Evans no líquido resultando da lavagem peritoneal. Observa-se também uma relação de dose-dependência para ambas as peçonhas e a mistura.

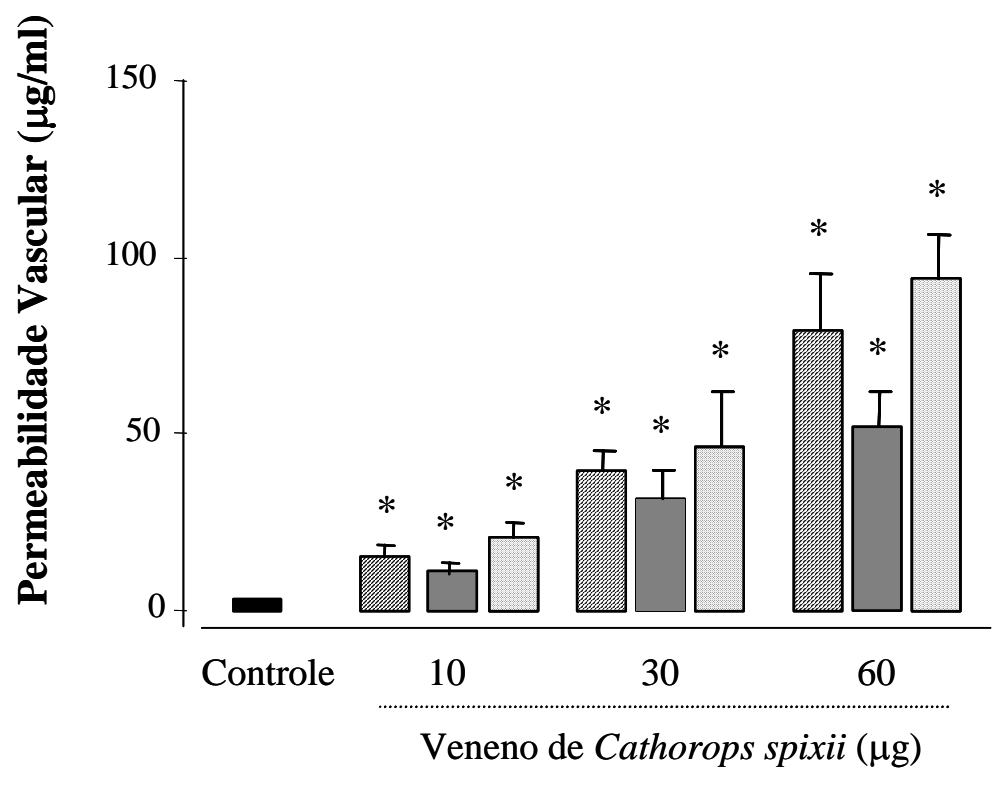

Salina 份Veneno do Muco $\square$ Veneno do Ferrão $\square$ Veneno do Muco + Ferrão

Figura 5. Aumento da Permeabilidade Vascular induzida pela ação das peçonhas do muco e do ferrão de Cathorops spixii. Camundongos foram injetados via i.p com as doses de 10,30 ou $60 \mu$ g das peçonhas do muco, do ferrão ou da mistura (muco+ferrão); 20 min antes do tempo definido para avaliação da permeabilidade ( $2 \mathrm{~h}$ ), avaliou-se quantidade do corante em $\mathrm{mg} / \mathrm{mL}$ de líquido resultante da lavagem peritoneal dos camundongos.

${ }^{*} \mathrm{p}<0,05$ em relação ao grupo-controle. 


\subsubsection{Alterações na Microcirculação e em Fibras Musculares}

Nas doses testadas, tanto a peçonha do muco quanto do ferrão, à concentração de $30 \mu \mathrm{g} / 20 \mu \mathrm{L}$ de PBS, induziram alterações na microcirculação (Figura 6), apenas nas vênulas pós-capilares, onde a partir de 10min da aplicação tópica de peçonha, pôde ser observado aumento significativo de leucócitos em processo de rolling e aderidos firmemente à parede do vaso. Após 30min, apenas a peçonha do muco, foi capaz de causar extase sanguínea, embora a peçonha do ferrão tenha causado a formação de inúmeros trombos, mas que não impediram totalmente o fluxo sanguíneo. Para ambas as peçonhas observou-se também, após 40min, desarranjo das fibras musculares do músculo cremaster.

O mesmo não foi observado nas arteríolas. Estes resultados são interessantes já que não foi observada atividade necrosante no modelo e dose testados. Para ambas as peçonhas observou-se também, após 40min, hipercontração miofibrilar. (Figura 7) 


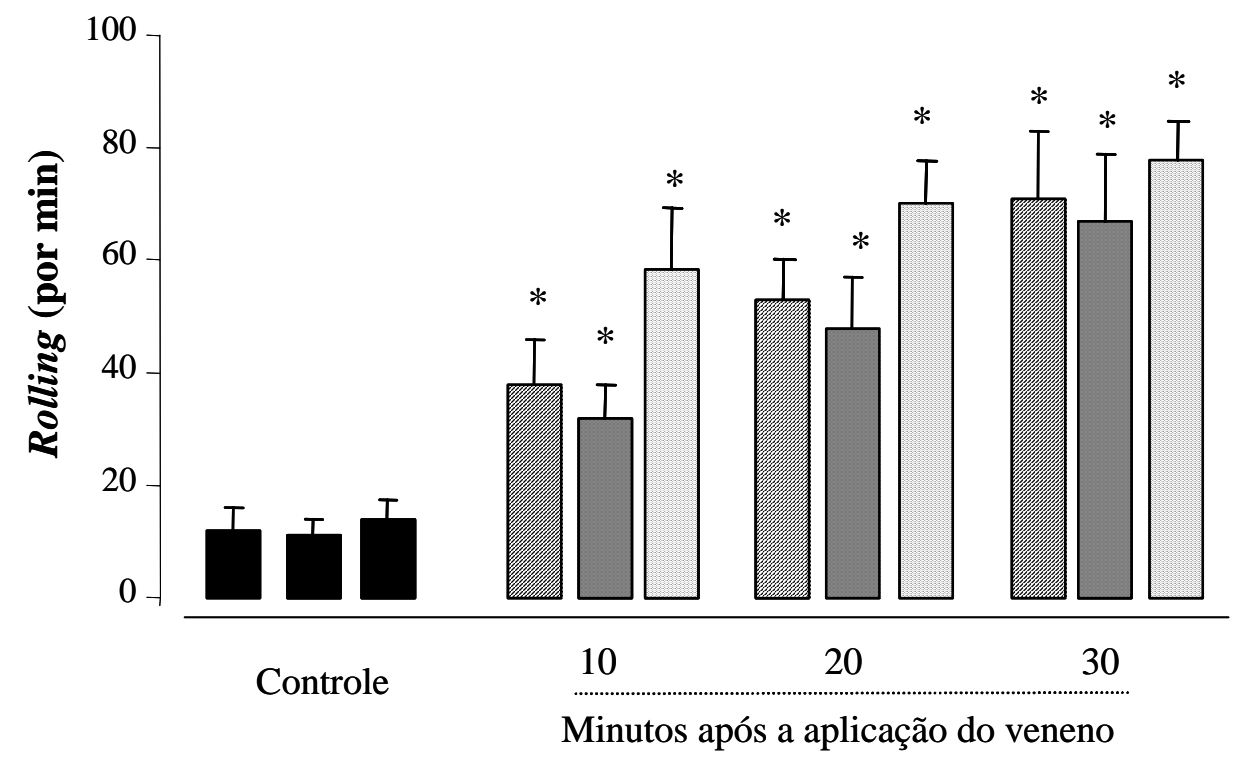

Salina $\square$ Veneno do Muco $\square$ Veneno do Ferrão $\square$ Veneno do Muco + Ferrão

Figura 6. Rolamento de leucócitos induzido pelas peçonhas do muco e do ferrão de Cathorops spixii. Camundongos, tiveram o cremaster exposto e o rolling de leucócitos foi observado nas vênulas pós-capilares, até 40min, após a aplicação tópica de $30 \mu \mathrm{g}$ das peçonhas do muco ou do ferrão. A aplicação de PBS foi utilizada como controle.

${ }^{*} \mathrm{p}<0,05$ em relação ao grupo-controle. 
(A)
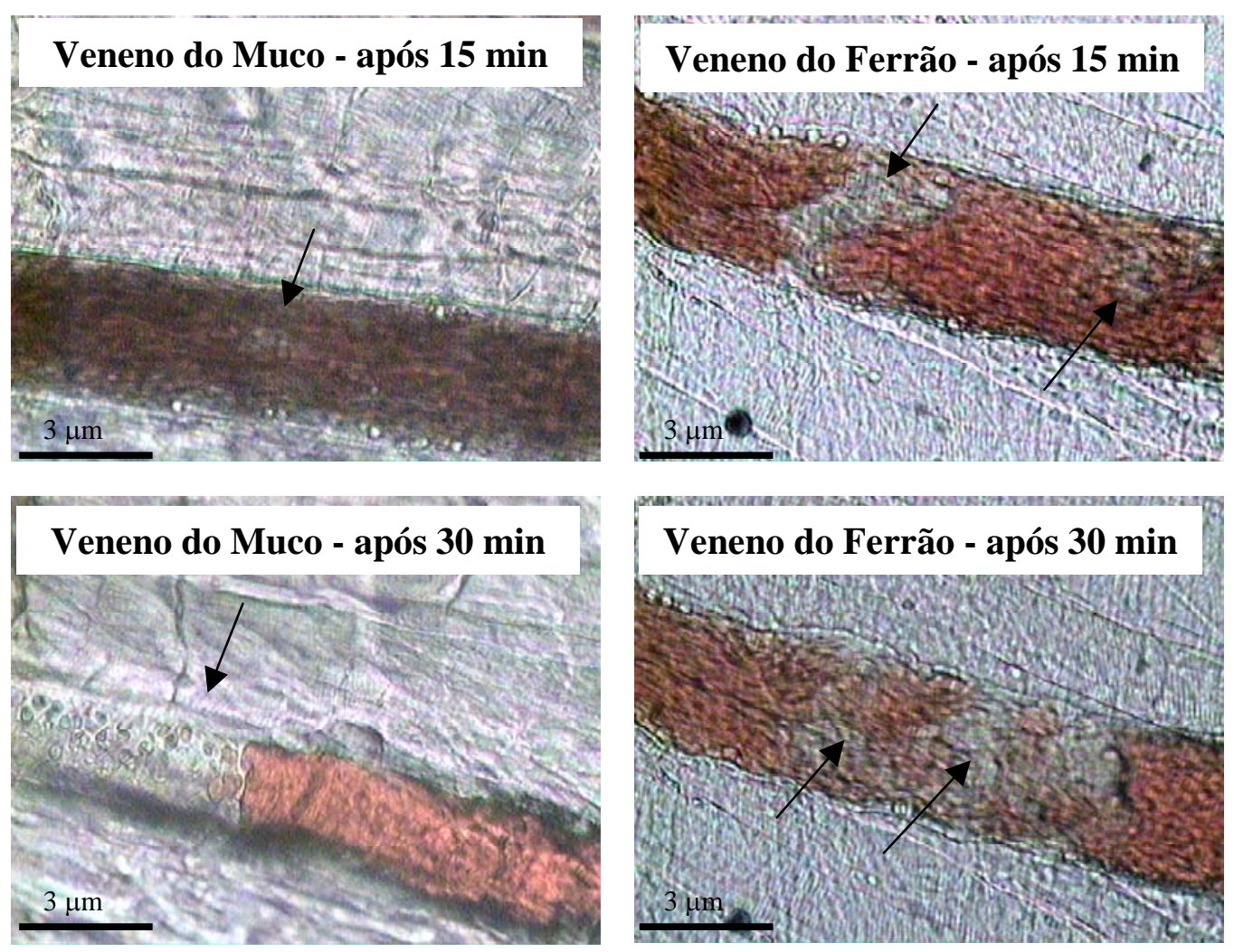

(B)
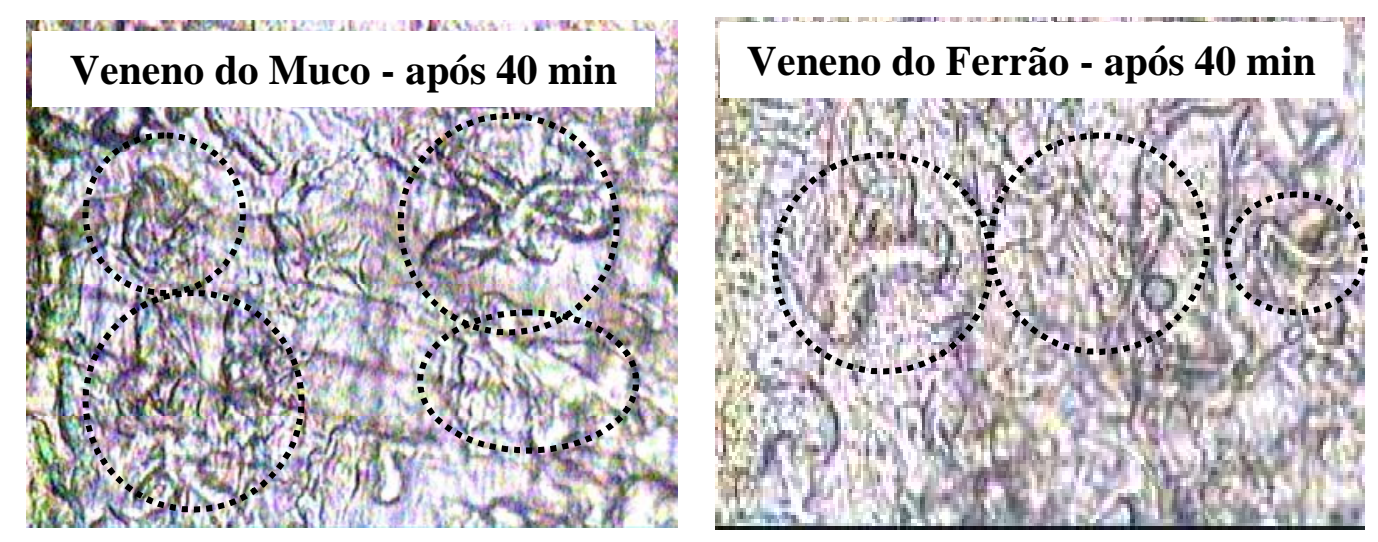

Figura 7. Ação observada na vênula pós-capilar do músculo cremaster de camundongos induzida pelas peçonhas de Cathorops spixii. Foram aplicados topicamente, em músculo cremaster exposto de camundongo (Swiss 20-22g), 30 $\mu$ das peçonhas do muco ou do ferrão. As alterações nas arteríolas, vênulas pós-capilares e fibras musculares foram observadas até 40min da injeção. A aplicação de PBS foi utilizada como controle. Em (A) observa-se, em vênulas pós-capilares, o rolling e a formação de trombos induzidos pelas peçonhas do muco e do ferrão; e extase sanguínea induzida pela peçonha do muco. Em (B) observa-se desarranjo nas fibras musculares induzida por ambas as peçonhas.

${ }^{*} \mathrm{p}<0,05$ em relação ao grupo-controle. 


\subsubsection{Atividade Proteolítica}

Quando comparados com o controle, ambas as peçonhas e a mistura foram capazes de induzir proteólise. Sendo esta mais evidente, quando a mistura foi aplicada ao substrato.

Tabela 1: Atividade proteolítica induzida pelas peçonhas do muco e do ferrão de C. spixii em camundongos

\begin{tabular}{lcccc}
\hline Proteolíse (U/mg) & $3 \mu \mathrm{g}$ & $10 \mu \mathrm{g}$ & $30 \mu \mathrm{g}$ & $60 \mu \mathrm{g}$ \\
\hline Veneno do Muco & $1.6 \pm 0.9$ & $2.3 \pm 0.8$ & $3.3 \pm 0.2$ & $3.5 \pm 0.9$ \\
Veneno do Ferrão & $1.1 \pm 0.9$ & $2.0 \pm 0.3$ & $2.5 \pm 0.2$ & $3.0 \pm 0.5$ \\
Veneno do Muco+Ferrão & $2.3 \pm 0.6$ & $2.9 \pm 0.6$ & $3.6 \pm 0.4$ & $3.9 \pm 0.5$ \\
\hline
\end{tabular}

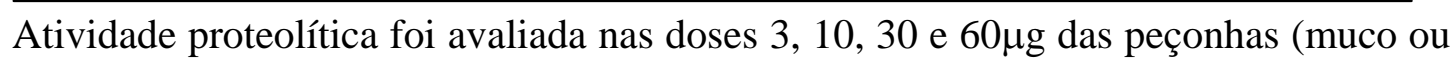
ferrão), ou a mistura (muco+ferrão), sobre a caseína. Resultados são expressos em U/mg de peçonha, a partir de 3 experimentos independentes.

\subsubsection{Atividades Necrosante e Hemorrágica}

De maneira interessante, as peçonhas não induziram hemorragia nem necrose no modelo e doses testados.

\subsection{ELETROFORESE DE PROTEÍNAS (SDS-PAGE)}

Ambas as peçonhas apresentam um perfil eletroforético complexo (Figura 8). Para o muco observamos sete componentes majoritários, um de massa molecular alta, que não entra totalmente no gel, um outro acima de $97 \mathrm{kDa}$, um com aproximadamente $97 \mathrm{kDa}$, dois entre 45 e $60 \mathrm{kDa}$ e dois entre 20 e $30 \mathrm{kDa}$. Na peçonha do ferrão foram visualizadas proteínas majoritárias na faixa dos 33 e acima dos 66 kDa. Diferenças são 
observadas entre as condições redutora e não redutora apenas nos grupos acima de $97 \mathrm{kDa}$.

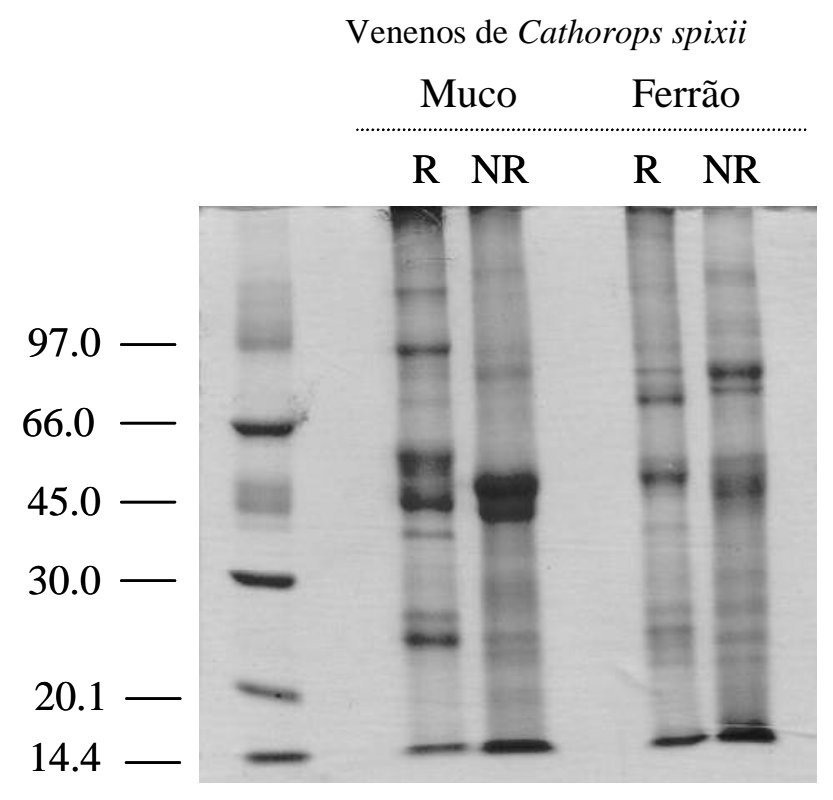

Figura 8: Perfil eletroforético das peçonhas de C. spixii. $10 \mu \mathrm{g}$ de proteína foram aplicados em gel de poliacrilamida (12\%) com adição de SDS em condições redutora (R) e não redutora (NR). Gel foi corado com Comassie Blue. Os números à esquerda correspondem aos marcadores de massa molecular Fosforilase B (97 kDa), Albumina (66 kDa), Ovalbumina (45 kDa), Anidrase carbônica (30 kDa), Inibidor de tripsina (20,1 kDa) e $\alpha$-Lactalbumina (14,4 kDa).

\subsection{FRACIONAMENTO}

O fracionamento em coluna de gel filtração mostra algumas diferenças entre proteínas do muco e do ferrão (Figura 9), evidenciadas principalmente pelos tubos 18/19 e 25/26, onde parecem existir proteínas na peçonha do ferrão que não se encontram na peçonha do muco.

Quando aplicamos o conteúdo dos tubos com maior absorbância (picos) em gel de eletroforese, SDS-PAGE, foi possível verificar que ainda há pouca separação, pois muitos tubos apresentam ainda bandas de proteínas com diversos pesos moleculares evidenciando que a separação por pesos moleculares nesta coluna não foi eficiente. 
Outros testes preliminares para separação, foram realizados através de coluna de Troca Catiônica (Mono - S) com tampão em pH 8,3 ou 5,0 e ainda assim não foi possível separar adequadamente as proteínas tanto da peçonha do muco, quanto do ferrão, o que sugere que as proteínas são aniônicas.

Ao submeter a peçonha do muco à solução em $\mathrm{pH}$ 5,0, houve precipitação, o que sugere que algumas proteínas tenham PI = 5,0, porém não foram realizados outros testes para comprovação

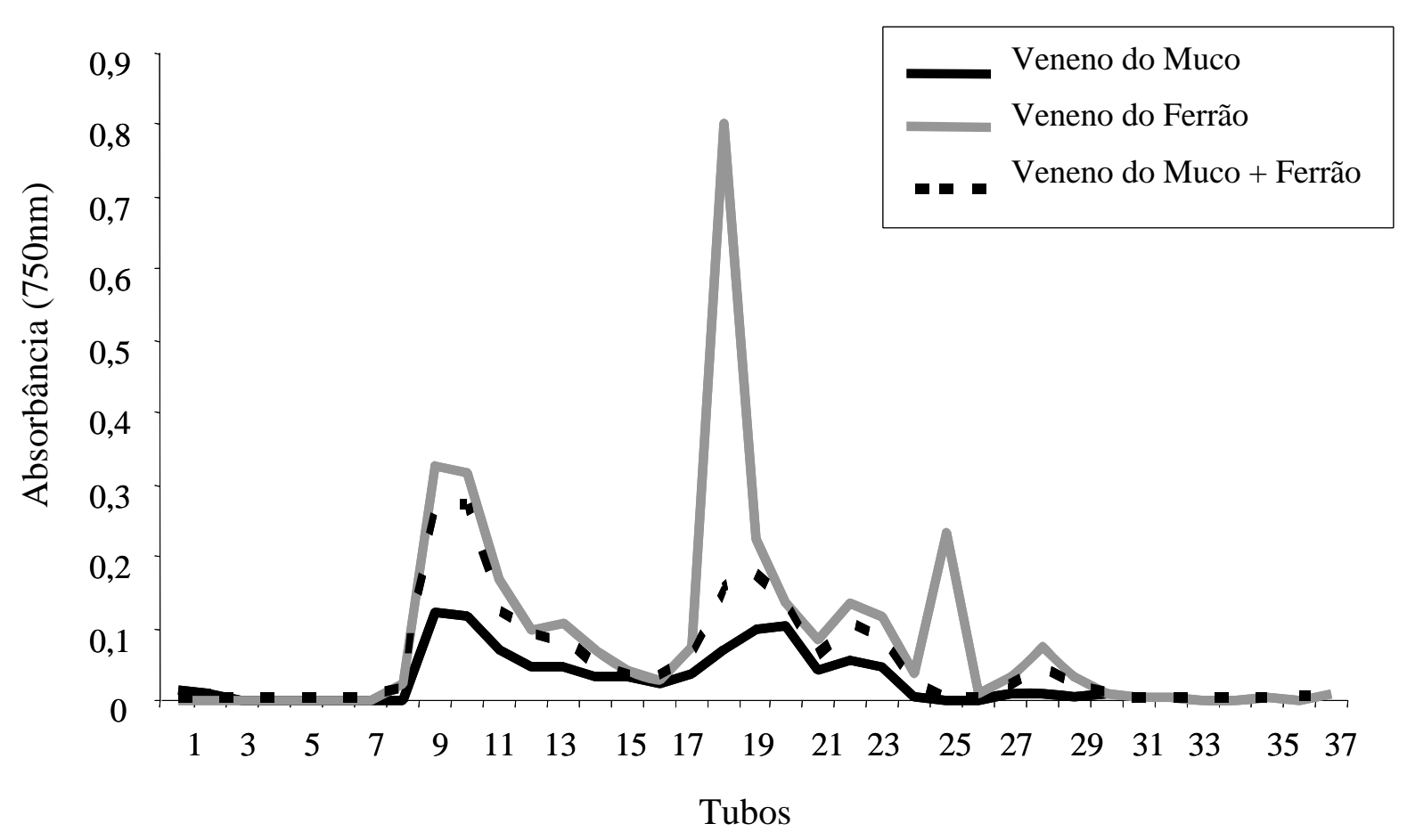

Figura 9. Cromatografia em coluna de Gel Filtração (Superdex - G75) das peçonhas do muco e do ferrão do bagre (Cathorops spixii). 


\section{Discussão}

Acidentes com bagres marinhos são muito comuns no litoral brasileiro, sendo eles um dos principais responsáveis pelos acidentes registrados com peixes peçonhentos no litoral de algumas regiões do País (Haddad Jr. \& Martins, 2006).

A clínica relata dificuldades no tratamento dos acidentados, mesmo após aplicação de antibióticos e antiinflamatórios, o que parece ser comum em acidentes com peixes, como ressaltado por Church \& Hodgson (2002); Lopes-Ferreira et al. (2000).

Ações tóxicas de dois dos três tipos de peçonhas encontrados no bagre amarelo Cathorops spixii foram analisadas, objetivando entender o envenenamento.

Dadas as limitações éticas e experimentais, de estudos com humanos, diversos modelos de injúria em tecidos têm sido desenvolvidos em animais a fim de reproduzir a cadeia de eventos de efeito local de peçonhas em tecidos (Sosa-Rosales et al., 2005).

Assim como caracterizado para os peixes do gênero Thalassophryne (Lopes-Ferreira et al., 1998; Sosa-Rosales et al., 2005) e Potamotrygon (Magalhães et al., 2005) há importante ação local, das peçonhas de bagre, em contraste ao que se observa, por exemplo, com as de Synaceja (stonefish) que costumam apresentar manifestações sistêmicas após o acidente.

Estas importantes ações locais, para as peçonhas de $C$. spixii foram caracterizadas por indução de importante nocicepção e edema em modelo murino, tal como o observado na clínica, em acidentes com humanos. (Haddad Jr. 2000; Haddad Jr. \& Martins, 2006). 
A dor neurogênica é causada por ação de toxinas nas terminações nervosas locais, ligando-se a receptores de dor (nociceptores), desencadeando a despolarização e conseqüente transmissão de impulso nervoso e sensação de dor. Ambos as peçonhas mostraram induzir nocicepção de fase neurogênica em modelo murino, o que sugere que estas peçonhas podem atuar diretamente em terminações nervosas e causar dor, independente da reação inflamatória e em proporções maiores do que a dor causada pelo ferimento causado pelos ferrões, o que está de extremo acordo com a clínica, onde se observa dor imediata e desproporcional ao tamanho da lesão (Haddad Jr. et al., 2003; Haddad Jr. \& Martins, 2006).

A dor inflamatória, por sua vez, pode ser resultado da ação de mediadores inflamatórios liberados por macrófagos e mastócitos residentes no local da lesão, da ação direta de células da inflamação sobre o tecido, ou por conseqüência do edema. Já que a formação de edema é uma conseqüência comum a processos inflamatórios cutâneos e é dependente de um sinergismo entre mediadores que aumentam a permeabilidade vascular e o fluxo sanguíneo (Brain \& Williams, 1985), com conseqüente extravasamento de líquidos e de células plasmáticas que acumulam nos espaços intercelulares.

O edema associado aa peçonha bruto de inúmeros outros peixes peçonhentos, já foram comprovados, podendo citar Synanceja horrida (Khoo et al., 1992), de Thalassophryne maculosa (Sosa-Rosales et al., 2005), do bagre Plotosus lineatus (Fahim et al., 2002), Thalassophryne nattereri (Lopes-Ferreira et al., 1998), Potamotrygon cf. orbygnyi e Potamotrygon gr. scobina (Magalhães et al., 2006), entre outros.

Assim como previamente reportado para Potamotrygon $c f$. orbygnyi e Potamotrygon gr. scobina (Magalhães et al., 2006), o bagre C. 
spixii induz um edema que regride entre 6 e 12 horas e de maneira menos intensa do que fora reportado para outros peixes (Lima, et al. 2003; SosaRosales et al., 2005).

Para T. nattereri, o mecanismo de ação para indução de nocicepção e edema foi elucidado; e está relacionado aos produtos da calicreína. (Lopes-Ferreira et al., 2004). Porém, para C.spixii encontra-se comprovado seu potencial pró-inflamatório, pela indução de peritonite em camundongos, quando injetados com peçonhas do muco ou do ferrão, que permaneceu por 7 dias, provocada pelo rápido influxo de neutrófilos e posteriormente, de macrófagos. A Análise das citocinas revelou que há significante liberação de LTB4, IL6, KC e MCP-1. (Junqueira et al., 2007).

Fazendo a relação entre edema a nocicepção de fase inflamatória, é interessante observar que a peçonha do muco foi mais eficaz na indução de edema, tal qual na nocicepção de fase inflamatória, sugerindo que estes dois processos estejam relacionados. Acrescenta-se a este, o fato de que, conforme fora publicado anteriormente (Junqueira et al., 2007) a peçonha do muco induz recrutamento imediato de neutrófilos e depois, de macrófagos; enquanto que a infiltração de células induzida pela peçonha do ferrão foi rapidamente resolvida, sugerindo que a nocicepção de fase inflamatória induzida de forma significativa e mais expressiva pela peçonha do muco, esteja relacionada ao recrutamento destas células inflamatórias. Além disso, Junqueira et al. (2007) também conclui que a resposta inflamatória induzida por C.spixii tem origens diferentes para cada peçonha.

A atividade proteolítica detectada para ambas as peçonhas é comparável à observada Thalassophryne nattereri (Lopes-Ferreira et al., 1998), Thalassophryne maculosa (Sosa-Rosales et al., 2005), 
Potamotrygon cf. orbygnyi e Potamotrygon gr. scobina (Magalhães et al., 2006).

O potencial pró-inflamatório das peçonhas, revelado pelo edema intenso e dor inflamatória, pôde ser confirmado com os ensaios em microscopia intravital. A aplicação tópica da peçonha na microcirculação causou aumento expressivo do rolling de leucócitos, efeito este que está relacionado à liberação local de mediadores vasoativos, citocinas e quimiocinas, que podem regular, e neste caso aumentar a expressão de moléculas de adesão que favorecem a adesão dos leucócitos.

As peçonhas de $P$. gr . orbygnyi e $P$. cf . scobina também induzem o aumento do rolling e adesão de leucócitos ao endotélio vascular, porém, este só pode ser observado após injeção subcutânea das peçonhas, indicando que as alterações na microcirculação são subseqüentes a um efeito inflamatório sistêmicos (Magalhães et al., 2006), enquanto que em C. spixii, observou-se esta ação após aplicação tópica das peçonhas, indicando ação inflamatória local. O que, conforme ressaltado por Junqueira et al. (2007) para C. spixii, explica-se já que ambas as peçonhas de $C$. spixii induzem aumento de adesão celular e liberação de níveis significativos de quimiocinas (MCP-1 e KC) e citocinas (IL-6) que atuam no recrutamento celular; sinais inflamatórios que precedem à transmigração destas células, dos vasos para o tecido afetado.

Sendo assim, o aumento da permeabilidade vascular, somado a redução ou paralisação do fluxo sanguíneo, parece ser o fator central das reações inflamatórias e é critico para a formação de um exudato inflamatório (Junqueira et al., 2007); causando edema e dor. Como os leucotrienos são produtos que exercem diferentes efeitos to tônus e na permeabilidade vascular (Brain \& Williams, 1985), o LTB4 pode ser o principal responsável pelos efeitos inflamatórios, dor, edema, aumento do 
rolling e aumento da permeabilidade vascular observados para ambas as peçonhas por Junqueira et al. (2007).

Também corroborando com os rápidos e intensos efeitos próinflamatórios, as peçonhas de C. spixii induziram formação de trombos, estase sanguínea (no caso da peçonha do muco) em vênulas pós-capilares hipercontração miofibrilar quando aplicados topicamente em músculo cremaster. Ação proteolítica também foi observada, porém, sem causar hemorragia, nem necrose, embora estes possam vez e quando ser observados na clínica com os acidentados (Haddad Jr. \& Martins, 2006).

De maneira semelhante a $C$. spixii, fora reportado que peçonhas de Thalassophryne nattereri (Lopes-Ferreira et al., 2001) e Thalassophryne maculosa (Sosa-Rosales et al., 2005) podem induzir formação de trombos, sem indução de hemorragia.

A hemorragia é uma conseqüência do envenenamento com vários animais peçonhentos e pode estar associada à presença de metaloproteinases (Ribeiro Filho et al., 2003) que são responsáveis por hemorragia local, já que degradam os componentes da membrana basal vascular, ocasionando total desintegração da estrutura do vaso (Baramova et al., 1989; Maruyama et al., 1992). Algumas enzimas hemorrágica purificadas de C. atrox, B. jararaca e L. muta possuem atividade fibrinolítica ou gelatinolítica (Maruyama et al., 1992; Bjarnason \& Fox, 1994; Estevão-Costa et al., 2000).

De maneira contrastante a C. spixii, as peçonhas de Thalassophryne nattereri (Lopes-Ferreira et al., 2001) e Thalassophryne maculosa (Sosa-Rosales et al., 2005) induzem severos danos ao tecido que em diversos casos foram relacionados a extase sanguínea e a desarranjos em fibras musculares. 
A necrose é resultado de lesão tecidual irreversível, causando morte celular e pode ser observada no acidente com diversos animais peçonhentos, geralmente devido às enzimas (como proteases e fosfolipases) que possuem. Embora nossos resultados mostrem que as peçonhas de bagre não são capazes de induzir necrose, atividades específicas, como PLA2 não foram testadas. Enzimas, como a hialuronidase, também são conhecidas por ser um componente importante, encontrados em muitas peçonhas que degradam o hialuronato, um dos maiores constituintes do tecido conectivo em animais. Acidentes com peixes, como o stonefish (peixe-pedra), causam extensiva necrose, provavelmente devido à hialuronidase encontrada em sua peçonha (Khoo, 2002).

$\mathrm{O}$ que sugere que os mecanismos de geração da necrose e relacionados a indução de estase sanguínea, proteólise e desarranjos nas fibras musculares, observados para T.maculosa (Sosa-Rosales et al., 2005), T. nattereri (Lopes-Ferreira et al., 2001), e igualmente observados para C.spixii não são semelhantes. Já que a presença destes não foi suficiente para causar necrose por C. spixii, mesmo em doses bastante altas. Ampliar o tempo de análise em microscopia intravital, observando a duração da estase sanguínea comparando-se as peçonhas destes peixes, bem como detalhando os mecanismos de ação destes para as atividades citadas, pode ser uma maneira de esclarecer estas diferenças.

A ausência de necrose nos modelos testados, mas sua presença ocasional na clínica pode estar relacionada, à infecção secundária pela contaminação das peçonhas por bactérias, conforme descrito por Junqueira et al. (2006) para o ferrão, onde se descreve a presença de 13 diferentes espécies de enterobactérias associadas ao ferrão de C. spixii na região de Santos (mesmo local onde foram coletadas as amostras 
utilizadas para o trabalho atual). Soma-se a isto o fato de a cultura popular ainda incentivar os acidentados a utilizar terra, urina, pó de café, ou até mesmo esfregar o olho do peixe na ferida, podendo agravar a contaminação.

Sendo assim, sugerimos que trabalho de educação sejam feitos às comunidades mais afetadas pelos acidentes com bagres, pois pelo menos a princípio, obtendo-se um atendimento rápido após o acidente e evitando-se aumentar a contaminação no local da lesão, a infecção secundária e suas complicações podem ser evitadas.

As peçonhas do bagre marinho Cathorops spixii apresentam perfil eletroforético complexo e com diferenças entre si, o que pode nos levar a compreender diferenças na indução das diferentes atividades tóxicas. A cromatografia também demonstrou diferenças entre os perfis das peçonhas, porém ainda não foi possível isolar seus componentes. Acredita-se que seja proteínas ácidas e que o PI de algumas proteínas do muco seja 5,0.

Assim, os resultados apresentados mostram que há importantes atividades tóxicas causadas pelas peçonhas do muco e do ferrão do bagre marinho Cathorops spixii, principalmente por conseqüência do quadro inflamatório induzido, de maneiras diferentes, pelas peçonhas. Isolar os componentes responsáveis por estas atividades, assim como analisar drogas que inativem estes componentes ou possam inibir as atividades tóxicas podem ser foco de estudo mais detalhado e de aplicação prática na clínica. 


\section{Conclusões}

Considerando-se os resultados apresentados quanto às atividades biológicas testadas e a caracterização preliminar da bioquímica das peçonhas do muco e do ferrão do bagre marinho Cathorops spixii, conclui-se que:

1. Baixas concentrações $(3 \mu \mathrm{g} / 30 \mu \mathrm{L})$ das peçonhas, isoladamente ou em conjunto, são capazes de induzir nocicepção significativa em camundongos;

2. Baixas concentrações $(3 \mu \mathrm{g} / 30 \mu \mathrm{L})$ das peçonhas, isoladamente ou em conjunto, são capazes de induzir edema significativo em camundongos, que se resolve até 24 horas após a injeção;

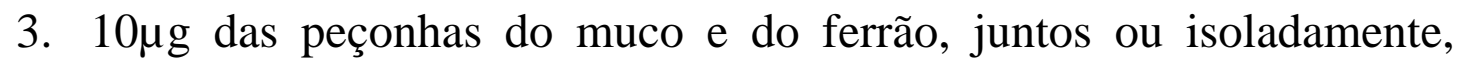
causam aumento da permeabilidade vascular em peritônio de camundongos após $2 \mathrm{~h}$ da injeção;

4. $30 \mu \mathrm{g} / 20 \mu \mathrm{L}$ de ambas as peçonhas são capazes de induzir alterações na microcirculação, como o aumento do rolling de leucócitos (após10 min da aplicação), extase sanguínea (após 30min, apenas no caso do muco) e contração miofibrilar (após40min) da aplicação tópica destas peçonhas no cremaster exposto de camundongos anestesiados;

5. A peçonha do muco e o do ferrão não induziram hemorragia nem necrose no modelo e doses testados;

6. Ambas as peçonhas e a mistura, a partir da dose de $3 \mu \mathrm{g}$, causaram proteólise quando aplicados em substrato de caseína. Neste caso, a ação foi mais efetiva quando da aplicação da mistura;

7. Ambas as peçonhas apresentam perfil eletroforético bastante complexo, apresentando proteínas, de forma mais evidente, acima 
de $97 \mathrm{kDa}$, com aproximadamente $97 \mathrm{kDa}$, entre 45 e $60 \mathrm{kDa}$ e entre 20 e $30 \mathrm{kDa}$, no caso da peçonha do muco. E na faixa dos 33 e acima dos 66 kDa no caso da peçonha do ferrão. Diferenças são observadas entre as condições redutora e não redutora principalmente nos grupos acima de $97 \mathrm{kDa}$.

8. A cromatografia em gel filtração não foi eficiente em separar os componentes protéicos de ambas as peçonhas, porém, evidencia diferenças entre os perfis. A peçonha do muco contém proteínas com PI próximo a 5,0. E o ferrão deve ser composto de proteínas primordialmente aniônicas. 


\section{Resumo}

Acidentes com peixes peçonhentos são muito freqüentes na região costeira do Brasil. Os bagres marinhos são os peixes peçonhentos que causam o maior número de acidentes no Brasil, especialmente no litoral sudeste, onde o bagre amarelo Cathorops spixii (Ariidae) é o mais abundante. O acidente é caracterizados por lesão dolorosa, edema intenso e ocasionalmente alguns sintomas sistêmicos. Embora estes sejam muito comuns, apenas nesta década, iniciaram-se os estudos sobre as ações das peçonhas. Sendo assim, este trabalho objetivou caracterizar as principais atividades tóxicas (edema, nocicepção, hemorragia, necrose, proteólise, alterações na permeabilidade vascular e na microcirculação) induzidas pelas peçonhas do muco e do ferrão de C. spixii em modelo murino (Swiss, 20-22g); bem como caracterizar algumas de suas propriedades bioquímicas. As peçonhas do muco e do ferrão e a mistura (muco+ferrão) foram testados. Nos ensaios de nocicepção e edema, as

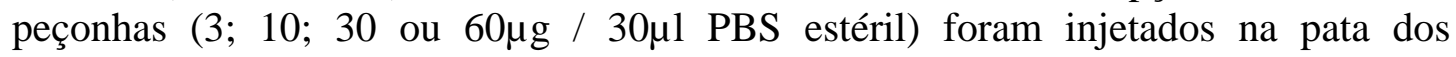

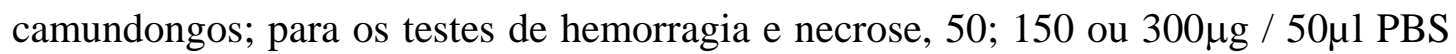
estéril foram injetados no dorso dos camundongos. Para a proteólise utilizou-se 3; 10; 30 ou 60 $\mu$ g sobre um substrato de caseína. Para a permeabilidade vascular, 10; 30 ou $60 \mu \mathrm{g}$ foram injetadas via i.p. Enquanto que as alterações na microcirculação utilizou-

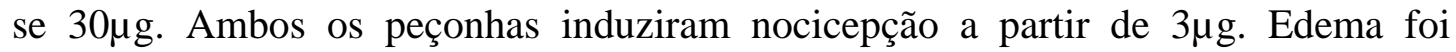
considerado significativo quando acima de $30 \%$ do controle. Todas as doses, para ambas as peçonhas foram capaz de induzi-lo, com pico após $2 \mathrm{~h}$ da injeção e permanecendo por até 24h. Hemorragia e necrose não foram induzidas, mesmo após a injeção de altas doses. A permeabilidade vascular foi observada após $2 \mathrm{~h}$ com todas as doses e peçonhas testados. As alterações na microcirculação foram observadas para

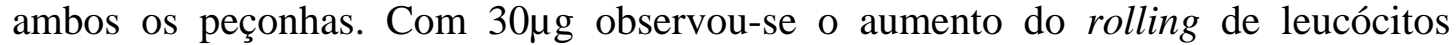
(após10 min), extase sanguínea (após 30min, apenas no caso do muco) e contração miofibrilar (após40min). SDS-PAGE (12\%) mostrou um perfil eletroforético bastante complexo, com proteínas majoritárias, acima de $97 \mathrm{kDa}$, com aproximadamente 97 $\mathrm{kDa}$, entre 45 e $60 \mathrm{kDa}$ e entre 20 e $30 \mathrm{kDa}$, no caso da peçonha do muco. E na faixa dos 33 e acima dos 66 kDa no caso da peçonha do ferrão. Diferenças são observadas entre as condições redutora e não redutora principalmente nos grupos acima de 97 $\mathrm{kDa}$. A cromatografia em gel filtração não foi eficiente em separar os componentes protéicos de ambos as peçonhas, porém, evidencia diferenças entre os perfis. A peçonha do muco contém proteínas com PI próximo a 5,0. E o ferrão deve ser composto de proteínas primordialmente aniônicas. Estes resultados mostram as importantes ações tóxicas induzidas pelas peçonhas do bagre marinho C. spixii, além de aspectos bioquímicos, que podem ser úteis no acompanhamento da evolução clínica e tratamento dos acidentados. 


\section{Abstract}

Accidents with venomous fishes are very frequent in costal waters of Brazil. Marine catfishes are the venomous fishes that cause the greatest number of accidents in Brazil, especially in southeast littoral, where the yellow-catfish Cathorops spixii (Ariidae) is the most abundant. The accident is characterized for painful injury, intense edema and some eventual systemic symptoms; and even these accidents are very commom, only in this decade, studies about its venoms had started. So this work intend to characterize the main toxic activities (edema, nociception, hemorrhage, necrosis, proteolysis, alterations is vascular permeability and in microcirculation) induced by mucus and sting venom of $C$. spixii in murine model (Swiss, 20-22g); besides its biochemical characterization. Mucus, sting and mixture (mucus+sting) venoms were tested. In nociceptive and edematogenic assays venoms (3; 10; 30 or $60 \mu \mathrm{g} / 30 \mu \mathrm{l}$ sterile PBS) were injected in mice paw, whereas in hemorrhagic and necrosis assays, venoms (50; 150 or $300 \mu \mathrm{g} / 50 \mu \mathrm{l}$ sterile PBS) were injected in mice back. To proteolytic assay, 10; 30 or $60 \mu \mathrm{g}$ were utilized over a casein substrate. To vascular permeability assay $10 ; 30$ or $60 \mu \mathrm{g}$ were injected by i.p. way. Whereas on microcirculation alterations $30 \mu \mathrm{g}$ were applied over exposed cremaster muscle.

All venoms induced nociception with $3 \mu \mathrm{g}$ or more. Edema was considered significant when over $30 \%$ of control group and was induced by all venoms, too, with bottom after $2 \mathrm{~h}$, and continuing until 24h. Hemorrhage and necrosis weren't observed even so high doses were injected. Alterations on microcirculation were observed for bath venoms. $30 \mu \mathrm{g}$ increased leukocyte rolling (after 10min), blood flow stopped (after 30min, but only with mucus venom), and caused contraction on miofibres (after 40min). SDS-PAGE (12\%) showed a complex pattern with several bands allover the gel. Skin and Sting venoms share some identical bands but there are important differences. Mucus venom majority bands are found between 20-30 kDa, 45-60 kDa and over $97 \mathrm{kDa}$. Sting venom major ones are between $33 \mathrm{kDa}$ and 55-60 kDa. GelFiltration (Sephadex) showed 4 (Mucus venom) and 5 peaks (Sting venom). In this differential peak, there are molecules with high molecular weight. These results show that both venoms are able to induce important toxic activities induced by mucus and sting venoms of $C$. spixii. Besides, biochemical aspects that can be useful to understand envenonming and propose better treatment. 


\section{Referências Bibliográficas}

Almeida, V. G.; Rocha, C. M. Registro de acidentes com peixes peçonhentos e/ou venenosos. Rev. Soc. Bras. Toxicol.,. v. 2, p. 49-51, 1989.

Auto, H. F. Acidentes por peixes peçonhentos Thalassophryne (Niquim), considerações em torno de 32 casos. Rev. Esc. Ciênc. Méd. Alagoas, v. 5, p. 35-36, 1992.

Al-Bow, H. A., Al-Hassan, J. M., Thomson, M., Thulesius, O., Elkhawad, A. Multiple vasoactive factors in epidermal secretions of the Arabian Gulf catfish, Arius bilineatus (Valenciennes). Gen. Pharmac., v.28, p. 737-744. 1997.

Al-Hassan, J. M., Dyson, M., Yound, S. R., Thomson, M., Criddle, R. S. Acceleration of wound healing responses induced by preparations from the epidermal secretions of the Arabian Gulf catfish (Arius bilineatus, Valenciennes). J. Wild. Med., v. 2, p. 153-163. 1991.

Al-Hassan, J. M. Diabetic ulcer healing preparations from the skin of the Arabian Gulf catfish (Arius bilineatus Val.), a novel and effective treatment. Int. J. Tissue React., v. 12, p. 121-35. 1990.

Al-Hassan, J. M, Ali, M, Thomson, M, Criddle, R. S. Prostaglandin associated mortality following intravenous injection of catfish epidermal secretions in rabbits. Prostaglandins Leukot. Med., v. 28, p. 95-102. 1987.

Al-Hassan, J. M., Thomson, M., Ali, M., Fayad, S., Elkhawad, A., Thulesius, O., Criddle, R. S. Vasoconstrictor components in the Arabian Gulf catfish (Arius thalassinus, Ruppell) proteinaceous skin secretion. Toxicon, v. 24, p. 1009-1014. 1986a.

Al-Hassan, J. M., Thomson, M., Summers, B., Criddle, R. S. Purification 
and properties of a hemagglutination factor from Arabian Gulf catfish (Arius thalassinus) epidermal secretion. Comp. Biochem. Physiol. B., v. 85, p. 31-39. 1986b.

Al-Hassan, J. M., Thomson, M., Criddle, K. R., Summers, B., Criddle, R. S. Catfish epidermal secretions in response to threat or injury. a novel defense response. Mar. Biol., v. 88, p. 117-123. 1985a.

Al-Hassan, J. M., Ali, M., Thomson, M., Fatima, T., Gubier, C. J. Toxic effects of the soluble skin secretion from the Arabian Gulf catfish (Arius thalassinus, Ruppell) on plasma and liver enzyme levels. Toxicon, v. 23, p. 532-534. 1985b.

Al-Hassan, J. M., Thomson, M., Criddle, R. S. Composition of the proteinaceous gel secretion from the skin of the Arabian Gulf catfish (Arius thalassinus). Mar. Biol., v. 70, p. 27-33, 1982.

Al-Lahhan, A., AL-Hassan, J. M., Thomson, M., Criddle, R. S. A hemolytic protein secreted from epidermal cells of the Arabian Gulf catfish, Arius thalassinus (Ruppell). Comp. Biochem. Physiol. B., v. 87, p. 321-327. 1987.

Auddy, B., Muhuri, D. C., Alam, M. I., Gomes, A. A lethal protein toxin (toxin PC) from the Indian Catfish Plotosus canius (Hamilton) venon. Nat Toxins v. 3 (5), p. 363-8. 1976.

Baez, S. An open cremaster muscle preparation for the study of blood vessels by in vivo microscopy. Microvasc. Res. 5, 384-396, 1973.

Baramova, E.N., Shannon, J.D., Bjarnason, J.B., Fox, J.W., 1989. Degradation of extracellular matrix proteins by hemorrhagic metalloproteinases. Arch. Biochem. Biophys. 275, 63-71.

Bjarnason, J.B., Fox, J.W., 1994. Hemorrhagic metalloproteinases from snake venoms. Pharmacol. Ther. 62, 325-372.

Bond, C. E. Biology of fishes. Philadelphia: Saunder College, 1979. 
Boylan, D. E., Scheuer, P. J. (1967) Pahutoxin: a fish poison. Science, 155:52-56.

Bradford, M. M. A rapid and sensitive method for quantitation of microgram quantities of protein utilizing the principle of protein dye binding. Anal. Biochem., 72, 248-54,1976.

Brain, S.D., Williams, T.J., 1985. Inflammatory oedema induced by synergism between calcitonin gene-related peptide (CGRP) and mediators of increased vascular permeability. Br. J. Pharmacol. 86 (4), 855-860.

Cameron, A.M., Endean, R., 1973. Epidermal secretions and the evolution of venom glands in fishes. Toxicon 11, 401-406.

Church, J. E., Hodson, W. C. The pharmacological activity of fish venoms. Toxicon, v. 40, p. 1083-93. 2002.

Clark, E. \& George, A. (1979) Toxic stoles, Pardachirus marmoratus from the Red Sea and P. pavoninus from Japan, with notes on other species. Environmental Biology of Fishes, 4:103-123

Criddle, R. S., Pierno, K., Thomson, M., Al-Hassan, J. M. Protein phosphorylation catalyzed by a secretion from epidermal cells. FASEB J. N 2, A995. 1988.

Cvetkovic, R. S., Figgit, D. P., Plosker, G. L. ET- 743. Drugs, v.62, p. 1185-1192. 2002.

Estevão-Costa, M.I., Diniz, C.R., Magalhães, A., Markland, F.S., Sanchez, E.F., 2000. Action of metalloproteinases mutalysin I and II on several components of the haemostatic and fibrinolytic systems. Thromb. Res. 99, 363-376.

Facó, P. E., Bezerra1, G. P., Barbosa1, P. S. F., Martins, A. M. C., Guimarães, J. A., Lopes-Ferreira, M, Monteiro, H. S. A. Epidemiology of the injuries caused by Thalassophryne nattereri 
(niquim) in Ceara State (1992-2002). Revista da Sociedade Brasileira de Medicina Tropical 38(6):479-482, nov-dez, 2005.

Fahim, F. A., Esmat, A. Y., Mady, E. A. Biological activities of the crude skin toxin of the Suez Gulf oriental catfish (Plotosus lineatus) and its antitumor effect in vivo (mice). J. Nat Toxins, v. 11, p. 283-295. 2002.

Ferreira, M. L.; Moura-DA-Silva, A.M.; França, F. O. S.; Cardoso, J. L.; Mota, I. Toxic activities of venoms from nine Bothrops species and their correlation with lethality and necrosis. Toxicon, v. 30, p. 16031608, 1992.

Figueiredo, J. L.; Menezes, N. A. Manual de Peixes Marinhos do Sudeste do Brasil: São Paulo: Museu de Zoologia, Universidade de São Paulo, 1980. p.14-18.

Figueiredo, J. L., Menezes, N. A. Manual de Peixes Marinhos do Brasil II. Teleostei (1). Muzeu de Zoologia - Universidade de São Paulo. São Paulo. p. 34-95. 1978.

Fonseca, L. A.; Lopes-Ferreira, M. Clinical and experimental studies regarding poisoning caused by a fish $T$. nattereri (niquim). Anais Brasileiros de Dermatologia, v. 75, n. 4, p. 435-443, 2000.

Freitas, J. C. (1999) Efeitos comportamentais de Neurotoxinas Guanidínicas em Meio Aquático. Revista de Ecologia, 1(2): 117-126.

Freitas, J. C. (1991) Nomenclatura em toxinologia: relações com a comunicação química entre os organismos e propriedades biológicas das toxinas. Memórias do Instituto Butantan, v. 53, n. 2, p. 191-195.

Freyvogel, T. A. \& Perret, B. A. Notes on toxinology. Experientia, 29(11): 1317-1452. 1973.

Goldberg, A. S., J., Renna, S., Reisman, H., Nair, M. S. R. (1982) Isolation and structure elucidation of an ichthyocrinotoxin from the 
smooth trunkfish (Lactophrys triqueter Linnaeus). Toxicon, 20:10691074.

Grund, L. Z.; Souza, V. M.; Faquim-Mauro, E.; Lima, C.; LopesFerreira, M. Experimental immunization with Thalassophryne nattereri fish venom: striking IL-5 production and impaired of B220+ cells. Toxicon, v. 48, p. 499-508, 2006.

Haddad, V.Jr, Martins, I. A. Frequency and gravity of human envenomations caused by marine catfish (suborder siluroidei): a clinical and epidemiological study. Toxicon 47 (8), 838-843. 2006.

Haddad Jr., V.; Pardal, P. P. O.; Cardoso, J. L.; Martins, I. A. The venomous toadfish Thalassophryne nattereri (niquim or miquim): Repor of 43 injuries provoked in fishermen of Salinópolis (Pará State) and Aracaju (Sergipe State). In: CONGRESSO DA SOCIEDADE BRASILEIRA DE MEDICINA TROPICAL, 49, p. 84. 2003.

Haddad Jr., V. Atlas de animais aquáticos perigosos do Brasil: guia médico de identificação e tratamento. São Paulo: Editora Rocca, 2000. p. 145.

Hara, T. J., Macdonald, S. Olfactory responses to skin mucous substances in rainbow trout Salmo gairdneri. Comp Biochem Physiol A. 1976;54(1):41-4. No abstract available.

Hashimoto Y; Oshima Y. Separation of grammistins A, B and C from a soapfish Pogonoperca punctata. Toxicon. May; 10(3):279-84. 1972.

Hunskaar, S., Hole, K. The formalin test in mice, p. dissociation between inflammatory and non-inflammatory pain. Pain, 30, p. 103-114. 1987

Kittredge, J. F., Takahashi, J.F.T., Lindsey, J., Lasker, R. (1974) Chemical signals in the sea: marine allelochemics and evolution. 
Bulletin of fisheries and wildlife services, 72(1):12

Junqueira, M. E. P. ;Grund, L. Z. ; Orii, N. M.; Saraiva, T. C.; Lopes, C. A. M.; Lima, C.; Lopes-Ferreira, M. Analysis of the inflammatory reaction induced by the catfish (Cathorops spixii) venoms. Toxicon, v. 49, p. 909-919, 2007.

Junqueira, M. E. P., Mondin, A. C., Lopes, C. A. M. Microbiota characterization of the catfish (Cathorops agassizii and Genidens genidens) sting venom. Brazilian Journal of Veterinary Research and Animal Science, Brasil, v. 43, n. 6, p. 1-10, 2006.

Khoo, H. E. Bioactive proteins from stonefish venom. Clin. Exp. Pharmacol. Physiol. v. 29, p. 802-806. 2002.

Khoo, H. E., Yuen, R., Poh, C. H., Tan, C. H. Biological activities of Synanceja horrida venom. Natural Toxins, v. 1, p. 54-60. 1992.

Kittredge, J. F., Takahashi, J.F.T., Lindsey, J., Lasker, R. Chemical signals in the sea: marine allelochemics and evolution. Bulletin of fisheries and wildlife services, 72(1):12, 1974.

Kizer, K. W. Marine envenomations. J.Toxicol. Clin. Toxicol. v. 21, p. 527. 1984.

Klaassen, , C. D., Watkins, J. B. (1999) Casarett and Doull's Toxicology: The basic Science of Poisons, Mcgraw-Hill, New York.

Laemmli, U. K. Cleavage of structural proteins during assembly of the head of bacteriophage T4. Nature ,v. 227, p. 680-685, 1970.

Lima, C., Clissa, P. B., Piran-Soares, A. A., Tanjoni, I., Moura-da-Silva, M. M., Lopes-Ferreira, M. Characterization of local inflammatory response induced by Thalassophryne nattereri fish venom in a mouse model of tissue injury. Toxicon, v. 42, p. 499-507. 2003

Lomonte B; Lungren J; Johansson B; Bagge U. The dynamics of local tissue damage induced by Bothrops asper snake venom and myotoxin 
II on the mouse cremaster muscle; an intravital. Toxicon 32, 41-55. 1994.

Lopes-Ferreira, M., Emim, J. A., Oliveira, V., Puzer, L., Cezari, M. H., Araújo, M. D. A., Juliano, L., Lapa, A. J., Souccar, C., Moura-daSilva, A. M. Kininogenase activity of Thalassophryne nattereri fish venom. Biochem Pharmacol. Dec 1;68(11):2151-7. 2004.

Lopes-Ferreira, M., Moura-da-Silva, A. M., Piran-Soares, A. A., Ângulo, Y., Lomonte, B., Gutierrez, J. M., Farsky, S. H. P. Hemostatic effects induced by Thalassophryne nattereri fish venom, p. a model of endothelium mediated blood flow impairment. Toxicon, v. 40, p. 1141-1147. 2002.

Lopes-Ferreira, M., Núñez, J., Rucavado, A., Farsky, S. H. P., Lomonte, B., Angulo, Y., Moura-da-Silva, A. M., Gutierrez, J. M. Skeletal muscle necrosis and regeneration after injection of Thalassophryne nattereri (niquim) fish venom in mice. Int. J. Exp. Pathol, v. 82, p. 5564. 2001.

Lopes-Ferreira, M.; Moura-da-Silva, A.M.; Mota, I.; Takehara, H.A. Neutralization of Thalassophryne nattereri (niquim) fish venom by an experimental antivenom. Toxicon, Vol.38, p 1149-1156, 2000.

Lopes-Ferreira, M., Barbaro, K. C., Cardoso, D. F., Mourda-da-Silva, A. M., Mota, I. Thalassophryne nattereri fish venom: biological and biochemical characterization and serum neutralization of its toxic activities. Toxicon, v. 36, p. 405-410. 1998.

Lowry O.H., Rosebrough, N. J., Farr, A C. Protein measurement with the foli-phenol reagent. J. Biol. Chem. 193, 265-275, 1951.

Magalhães, GS.; Junqueira-de-Azevedo, Lopes-Ferreira, M.; Lorenzini, DM.; Ho, PL.; Moura-da-Silva AM. Transcriptome analysis of 
expressed sequence tags from the venom glands of the fish Thalassophryne nattereri. Biochimie, 2006.

Magalhães, G.S.; Lopes-Ferreira, M.; Junqueira-de-Azevedo, M.I.L.; Spencer, P.J.; Araújo, M.S.; Portaro, F.C.V.; Ma, L.; Valente, R.H.; Juliano, L.; Fox, J.W.; Ho, P.L.; A.M. Moura-da-Silva. Natterins, a new class of proteins with kininogenase activity characterized from Thalassophryne nattereri fish venom. Toxicon, v.87, p. 687-699. 2005.

Mandelbaum, F. R., Reichl, A P., Assakura, M. T. Isolation and characterization of a proteolytic enzyme from the venom of Bothrops jararaca (jararaca). Toxicon 28, 1293-1301, 1990.

Maretic, Z. Fish venoms. (1988) In: Tu, A. T., (Ed.), Handbook of Natural Toxins: Marine Toxins and Venoms, Marcel Dekker, New York, pp.445-477.

Maruyama, M., Sugiki, M., Yoshida, E., Shimaya, K., Mihara, H., 1992. Broad substrate specificity of snake venom fibrinolytic enzymes: possible role in haemorrhage. Toxicon 30, 1387-1397.

Monteiro, H. S A., Bezerra, G. P., Facó, P. E. G., Havt, A., Siva-Jr., G. B. Epidemiologia dos acidentes pelo peixe Niquim (T. nattereri) no estado do Ceará no período de 1992 a 2002. In: Congresso da Sociedade Brasileira de Medicina Tropical, v. 49. p.11.2003

Nelson, J.S., Fishes of the World. 3rd ed. John Wiley \& Sons, Inc., New York, 600 p, 1994.

Nuijen, B., Bouma, M., Henrar, R., Manda, C., Bult, A., Beijnen, J. H. Compaibility and stability of aplidine, a novel marine-derive depsipeptide antitumor agent in infusion devices, and upon i.v. administration. Anti-cancer Drug, v. 10, p. 879-886. 1999.

O’Connor, J. M., Hahn, S. T.; Brooks, L. From venom to pain research: a 
novel use of a Scorpaenidae venom. Biological Research for Nursing, v. 6 (2), p. 100-109. 2004

Olivera B. M., Rivier J., Clark C., Ramilo C. A., Corpuz G. P., Abogadie F. C., Mena E. E., Woodward S. R., Hillyard D. R., Cruz L. J. Diversity of Conus neuropeptides. Science, v. 249, p. 257-63. 1990.

Pardal, P. P. O., Resende Aspectos Clínicos e Terapêuticos dos Acidentes por Animais Peçonhentos. Ed. EPUB, 321p. 1999.

Piran-Soares, A. A.; Komegae, E. N.; Souza, V. M. O.; Fonseca, L. A.; Lima, C.; Lopes-Ferreira, M. Neutralizing antibodies obtained in a persistent immune response are effective against deleterious effective against deleterious affects induced by the Thalassophryne nattereri fish venom. Toxicon, v. 49, p. 920-930, 2007.

Randall, J. E., Aida, K., Oshima, Y. Hori, K., Hashimoto, Y. Occurrence of a crinotoxin hemagglutinin in the skin muçus of the moray eel, Lycodonis nudivomer. Mar. Biol. 62, 179, 1981.

Randall, J. E., Aida, K., Hibiya, T. Mitsuura, N., Kamiya, H., Hashimoto, Y. Grammistidin, the skin toxin of soapfishes, and its significance in the classification of the Grammistidae. Publs. Seto Mar. Biol. Lab. 19, 157-190, 1971.

Reis, E. G. A pesca artesanal de bagres marinhos (Siluriformes, Ariidae) no Estuário da Lagoa dos Patos, RS. Documentos Técnicos. 05, Furg. Rio Grande do Sul, 22p. 1986.

Ribeiro Filho, W., Sugiki, M., Yoshida, E., Maruyama, M. Inhibition of hemorrhagic and edematogenic activities of snake venoms by a broad-spectrum protease inhibitor, murinoglobulin; the effect on venoms from five different genera in Viperidae family. Toxicon, v. 42 p. $173-81.2003$

Rinehart, K. L. Antitumor componds from tunicates. Med Res Rev, v. 20, 
p. 1-27. 2000.

Russel, F. E. (1996) Toxic effects of animals toxins. In: klaassen, C.D.,

(Ed.), Casarett and Doull's Toxicology - The Basic Science of poison, Mcgraw-Hill, Sydbey.

Russell, F. E. Pharmacology and toxinology of naturally occurring toxins. Oxford, Pergamon Press, v. 2, p. 1-114. 1971.

Russell, F. E. Comparative pharmacology of some animal toxins. Federation Proc., 26(4):1206-1223. 1967.

Rucavado, A., Escalante, T., Franceschi, A., Chaves, F., Leon, G., Cury, Y., Ovadia, M., Gutierrez, J.M., 2000. Inhibition of local hemorrhage and dermonecrosis induced by Bothrops asper snake venom: effectiveness of early in situ administration of the peptidomimetic metalloproteinase inhibitor batimastat and the chelating agent CaNa2EDTA. Am. J. Trop. Med. Hyg. 63, 313-319.

Scotto, K. W. ET-743, p. More than an innovative mechanism of action. Anti-cancer drug., v. 13, p. 3-6 (Suppl. 1). 2002.

Sirois MG, Jancar S, Braquet P, Plante GE, Sirois P. PAF increases vascular permeability in selected tissues: effect of BN-52021 and L655,240. Prostaglandins. Nov;36(5):631-44, 1988.

Sosa-Rosales, J. I., Piran-Soares, A. A., Farsky, S. H., Takehara, S. H., Lima, C., Lopes-Ferreira, M. Important biological activities induced by Thalassophryne maculosa fish venom. Toxicon, v. 45, p. 155-61. 2005.

Summers, B., Criddle, R. S., Thomson, M., Al-Hassan, J. M. Arius thalassinus blood coagulation factor enters the normal clotting cascade at factor X. Fed. Proc. 44, p. 1844. 1985.

Sutherland, S. Australian Animal Toxins. $1^{\text {st }}$ edition, Oxford University Press. 1983. 
Tachibana, K. (1984) Shark-repelling ichthyotoxins from the defensive secretion of the sole Pardachirus pavoninus. In L. Bolis, J. Zadunarsky \& R. Gilles (Eda.), Toxins, drugs and pollutants in marine animals (p 2-12), Berlin Heidelberg: Springer-Verlag.

Thomson, M., Assad, H., Al-Hassan, J. M., Criddle, R. S. An acid phosphatase secreted from the skin of the Arabian Gulf catfish, Arius bilineatus. FASEB J. 4, A2234. 1990.

Thomson, M., Al-Hassan, J. M., Fayad, S., Criddle, R. S. Tyrosine specific sterase activity in the epidermal secretions of the Arabian Gulf catfish, Arius bilineatus (Valenciennes). Comp. Biochem. Physiol., v. 93B, p. 621-627. 1989.

Thomson, M., Al-Hassan, J. M., Fayad, S., Criddle, R. S. Esterase activities of the proteinaceous gel secretion from the skin of the Arabian Gulf catfish (Arius bilineatus). Fed. Proc. 43, p. 1953. 1984.

Thulesius, O., Al-Hassan, J. M., Criddle, R. S., Thomson, M. Vascular responses elicited by venom of Arabian catfish (Arius thalassinus). Gen. Pharmacol. v. 14, p. 129-132. 1983.

Van-Kesteren, C., Twelves, C., Bowman, A., Hoekman, K., LopesJazaro, J. J., Guzmán, C., Mathot, R. A., Simpson, A., Vermorken, J. B., Smyth, J., Schellens, J. H., Hillebrand, M. J., Rosing, H., Beijnen, J. H. Clinical pharmacology of the novel marine derived anticancer agent ecteinascidin in a phase I study. Anticancer drugs, v. 13, p. 381-393. 2002.

Williamson, L. A. (1995)Clinical toxicology of venomous Scorpaenalidea and other selected fish stings. In: Meier, J., White, J. (eds.), Clinical Toxicology of Animal Venoms and Poisons, CRC Press, Florida, pp. 142-158. 


\section{Biografia}

\section{FORMAÇÃO ACADÊMICA/TITULAÇÃO}

2004 - 2004 - Aperfeiçoamento em Toxinas, Anticorpos monoclonais e Imunodiagnóstico. Instituto Butantan, IBU, São Paulo, Brasil - Orientador: Mônica Lopes Ferreira. Bolsista do(a): Fundação do Desenvolvimento Administrativo

1999 - 2003 - Graduação em Ciências Biológicas - Bacharelado e Licenciatura. Universidade Estadual Paulista Júlio de Mesquita Filho, UNESP, São Paulo, Brasil

\section{PRODUÇÃO BIBLIOGRÁFICA RELACIONADA AO TEMA DA DISSERTAÇÃO.}

\section{Publicação Completa em Revista Científica}

1. JUNQUEIRA, M. E. P., MONDIN, A. C., LOPES, C. A. M. Microbiota characterization of the catfish (Cathorops agassizii and Genidens genidens) sting venom.

\section{Resumos Publicados em Anais de Congressos}

1. JUNQUEIRA, M. E. P., MONDIN, A. C., LOPES, C. A. M., LOPES-FERREIRA, M. Skin venom of the catfish Genidens genidens induces nociception and edema In: VI Reunião Científica Anual do Ianstituto Butantan, 2005, São Paulo. Memórias do Instituto Butantan. , 2005.

2. MONDIN, A. C., JUNQUEIRA, M. E. P., LOPES-FERREIRA, M. Toxic activities and biochemical characterization of catfish (Cathorops spixii) skin and sting venoms In: VI Reunião Científica Anual do Instituto Butantan, 2005, São Paulo. Memórias do Instituto Butantan. , 2005.

3. JUNQUEIRA, M. E. P., MONDIN, A. C., LOPES, C. A. M., LOPES-FERREIRA, M. L. Eletrophoretical characterization and indution of edema and nociception by the skin venom of the catfish Genidens genidens In: VIII Congresso da Sociedade Brasileira de toxinologia (sbtx) e VIII Simpósio da Seção Pan Americana da Sociedade International de Toxinologia (IST), 2004, Angra dos Reis. Journal of Venomus Animals and Toxins incl. Tropical Diseases. , 2004. V.10. P.459 - 459

4. MONDIN, A. C., JUNQUEIRA, M. E. P., LOPES-FERREIRA, M. Toxic activities and biochemical characterization of catfish (Cathorops spixii) skin and sting venoms In: VIII Congresso da Sociedade Brasileira de Toxinologia (sbtx) e VIII Simpósio da Seção Pan Americana da Sociedade Internacional de Toxinologia (IST), 2004, Angra dos Reis. Journal of Venomous Animals and Toxins incl. Tropical Diseases. , 2004. V.10. P.410 - 410

5. JUNQUEIRA, M. E. P., MONDIN, A. C., LOPES-FERREIRA, M., LOPES, C. A. M. Microbiota e características eletroforéticas das proteínas dos venenos enconrados 
nos ferrões das espécies de bagres Cathorops spixii e Genidens genidens. In: XVIII Simpósio de Biologia Marinha, 2003, São Sebastião. Caderno de Resumos do XVIII Simpósio de Biologia Marinha. , 2003.

6. MONDIN, A. C., JUNQUEIRA, M. P., LOPES-FERREIRA, M., RAMOS, P. R. R. Peçonhas de bagres marinhos: perfil eletroforético. In: $6^{\circ}$ Encontro Regional de Biomedicina, 2003, Botucatu - SP. Caderno de Resumos do $6^{\circ}$ ERBM. , 2003.

7. MONDIN, A. C., LOPES-FERREIRA, M. Preliminary characterization of catfish Cathorops spixii skin secretions In: V Reunião Científica Anual do Instituto Butantan, 2003, São Paulo. Memórias do Instituto Butantan. , 2003. V.60. P.140 140

8. MONDIN, A. C., JUNQUEIRA, M. P., LOPES-FERREIRA, M. Respostas nociceptiva e edematogênica induzidas pela peçonha do bagre marinho Arius spixii. In: Encontro Regional de Biomedicina, 2003, Botucatu - SP. Caderno de Resumos do $6^{\circ}$ ERBM. , 2003. 